Columbia Law School

Scholarship Archive

\title{
Being True to Trulia: Do Disclosure-Only Settlements in Merger Objection Lawsuits Harm Shareholders?
}

\author{
Eric L. Talley \\ Columbia Law School, etalley@law.columbia.edu \\ Giuseppe Dari-Mattiacci \\ Amsterdam Law School
}

Follow this and additional works at: https://scholarship.law.columbia.edu/faculty_scholarship

Part of the Banking and Finance Law Commons, Business Organizations Law Commons, and the Law and Economics Commons

\section{Recommended Citation}

Eric L. Talley \& Giuseppe Dari-Mattiacci, Being True to Trulia: Do Disclosure-Only Settlements in Merger Objection Lawsuits Harm Shareholders?, (2019).

Available at: https://scholarship.law.columbia.edu/faculty_scholarship/2303

This Working Paper is brought to you for free and open access by the Faculty Publications at Scholarship Archive. It has been accepted for inclusion in Faculty Scholarship by an authorized administrator of Scholarship Archive. For more information, please contact scholarshiparchive@law.columbia.edu. 


\title{
Being True to Trulia: Do Disclosure-Only Settlements in Merger Objection Lawsuits Harm Shareholders?*
}

\author{
Giuseppe Dari-Mattiacci†and Eric Talley ${ }^{\ddagger}$
}

March 7, 2019

\begin{abstract}
A significant debate within mergers and acquisitions law concerns the explosive popularity of the "merger objection lawsuit" (MOL), a shareholder action seeking to enjoin an announced deal on fiduciary duty grounds. MOLs blossomed during the Financial Crisis, becoming popularly associated with "shareholder shakedowns," whereby quick-triggered plaintiff attorneys would file against-and then rapidly settle with - acquirers, typically on non-monetary terms containing modest added disclosures in exchange for blanket class releases and attorney fee awards. This practice unleashed a torrent of criticism from lawyers, commentators, academics, and (ultimately) judges, culminating in a doctrinal shift in Delaware law in the early 2016 Trulia opinion, which virtually prohibited disclosure-only settlements. This paper investigates the implications of this doctrinal shock from a shareholder welfare perspective. We argue that - notwithstanding the seemingly intuitive case against disclosure settlements - it is far from clear whether discouraging them helps or hurts target shareholders ex ante, since the threat of MOLs interacts with other intra-corporate agency costs (such as those of managers and buyers negotiating deals). Reducing the credibility of a litigation threat may deter shakedowns at the cost of reduced deal premia and shareholder value - consequences inconsistent with conventional commitments of corporate law. We develop a theoretical model of company acquisitions formally demonstrating that the competing equilibrium effects of Trulia are indeterminate, an insight that hoists a flag of caution regarding the doctrinal innovation. Moreover, our model delivers testable implications related to Trulia, which we investigate empirically. Our analysis suggest that the recent doctrinal shock does not appear to have resulted in a discernible increase to target shareholder welfare.
\end{abstract}

JEL: G30, G34, K20

Keywords: mergers and acquisitions, suit and settlement, shareholder class actions, agency costs.

\footnotetext{
*The authors thank Emiliano Catan, Sean Griffith, Sharon Hannes, Avi Tabbach and participants in the seminar at Columbia, Tel Aviv University, University of Illinois, the 2016 Law and Economics Theory Conference at NYU, and the 2017 American Law and Economics Association Annual Conference for insightful comments, and Edward Rivera for research assistance. All errors are ours.

${ }^{\dagger}$ Amsterdam Law School.

‡Columbia Law School.
} 


\section{Introduction}

Among mergers and acquisitions (M\&A) practitioners, it had become commonplace (at least until recently) to anticipate shareholder litigation on the heels of most public company acquisitions. Under some accountings (Cain and Davidoff Solomon, 2015, 2016), the frequency of litigation following executed deals over $\$ 100$ million nearly doubled between 2005 and 2014, from less than one in two to over nine in ten. ${ }^{1}$ When employed deftly, such "merger objection lawsuits" (MOLs) represent significant sources of transactional delay, cost and liability exposure - an annoyance at minimum, and potentially a deterrent to value-enhancing transactions.

Given the stakes involved, it is perhaps not surprising that most MOLs settle-particularly when deal closure hangs in the balance. Somewhat more noteworthy, however, is the progressively defanged character of MOL settlements during the last decade. At the turn of the $21^{\text {st }}$ century, around half of all MOLs settled with cash awards, with many of the remainder including substantive amendments to deal terms. By the end of 2014, in contrast, nearly four in five MOL settlements made no material transactional amendments or price adjustments whatsoever, mandating instead only additional public disclosures to target shareholders, the content of which routinely seemed unexceptional (if valuable at all). While seemingly inconsistent with the existence of a credible lawsuit in the first place, such peppercorn settlements are perfectly understandable when one considers the interests of the principal negotiating parties. On the one hand, defendants value broad blanket releases from future shareholder claims, allowing the signed deal to close and minimizing prospective exposure. $^{2}$ On the other, plaintiff attorneys typically win generous compensation for their time, under the theory that the attorney's effort created a "common fund" and/or a "corporate benefit" for target shareholders, thereby justifying an attorney fee award. ${ }^{3}$ Such fee awards can be lucrative, averaging nearly $\$ 500,000$ even in disclosure-only settlements (a figure that scales up somewhat depending on when the settlement occurs and its underlying terms).

The rise of disclosure settlements soon caught the attention (and, by and large, the derision) of commentators. Several decried this trend at length (e.g.: Griffith, 2015; Fisch, Griffith, and Davidoff Solomon, 2015), arguing (inter alia) that the supplemental disclosures that come from such settlements are ineffectual in altering shareholder support in approving mergers. This lack of effect, in turn, calls into question not only the value that plaintiff attorneys add for their nominal clients, but also the value of MOLs writ large. Some commentators have advocated for the blanket exclusion of attorney fees for non-monetary settlements, effectively nullifying the common benefit doctrine in such cases. ${ }^{4}$

The crescendo of criticism around disclosure settlements eventually found a ready audience in the Delaware judiciary. Indeed, it already had one, since several Chancery Court judges had, by turns, expressed skepticism about the desirability of such practices since at least 2009. ${ }^{5}$ Nevertheless, starting in late 2015, a series of important Chancery Court holdings from different judges began to signal enhanced judicial scrutiny of disclosure settlements. This direction became firmly cemented in early 2016, with Chancellor Bouchard's

\footnotetext{
${ }^{1}$ During this same time, it became common for such litigation to be commenced across multiple judicial fora, often (but not always) including the state of incorporation of the (nominal) defendant corporation (Cain and Davidoff Solomon, 2015).

${ }^{2}$ See, e.g., Markel and Burns (2015), available at http://www.law360.com/articles/728061/assessing-a-judicial-solution-toabusive-merger-litigation.

${ }^{3}$ See, e.g., Sugarland Industries, Inc. v. Thomas, 420 A.2d 142 (Del. 1980).

${ }^{4}$ See, e.g., Fisch, Griffith, and Davidoff Solomon (2015, 612) ("perhaps the most straightforward approach for eliminating fee awards in disclosure-only settlements would be for courts to stop recognizing disclosure-only settlements as producing a shareholder benefit sufficient to entitle plaintiffs' lawyers to a fee award. Because the corporate benefit doctrine is a judicially created doctrine, courts could implement this change themselves"); Griffith $(2015,47)$ (arguing that the corporate benefit doctrine should "no longer [be] recognized as a justification for fee awards in the class action context," and that if such a reform were enacted, plaintiffs "could not recover attorneys' fees on the basis of non-pecuniary relief").

${ }^{5}$ Some commentators have identified the kernel of the sea change as occurring in the now well-known Rural/Metro litigation, which in 2012 had originally been settled on a disclosure-only basis, but later overturned by Vice Chancellor Laster. See Friedlander (2016).
} 
opinion in In re Trulia, Inc. Stockholder Litigation ${ }^{6}$ which dramatically shifted the doctrinal landscape for settlement approval, requiring proponents of a disclosure settlement to demonstrate the added disclosures to be "plainly material" (or in the alternative to come forward with a settlement entailing something beyond disclosure, such as altering the acquisition's price or non-price terms). The effects of Trulia have been discernible among practicing litigators, as the rate of merger objection lawsuits fell substantially compared to the rate of MOL litigation prior to the judicial sea change. ${ }^{7}$

In many respects, the building skepticism over disclosure-only settlements - and the culminating jolt introduced by Trulia - represent an important lesson about myopic infatuation with "managerial" agency costs: Much of corporate law focuses on identifying and regulating the incentive problems that pervade the relationship between those who own companies and those who manage them. Such attention seems richly deserved in the M\&A context, where target boards and managers can be particularly prone to elevating their own private interests above that of shareholders. And yet, the principal tool that the law gives shareholders for redressing managerial malfeasance - the shareholder lawsuit - can incubate other forms of agency cost: The procedural rules governing shareholder class actions cede considerable control and authority over an MOL to the plaintiff attorney. It is generally she who recruits the client, commences litigation, negotiates a settlement and petitions for fees. And, just as managers may elevate their own interests above shareholders' in structuring a deal, plaintiff-side attorneys may put their own incentives above their passive shareholderclients' interests in structuring a settlement - executing "peppercorn" agreements that manage to do little beyond generating a fee award. Factor in the willing confederate that plaintiff counsel typically finds in the defendant (who is anxious to secure a release and close the deal), and the disclosure settlement becomes a near-perfect storm for lawyer-borne agency costs, with shareholders (yet again) taking it in the chops. If fact, as one commentator documented, disclosure settlements appear to have helped cultivate a new class (or possibly underclass) of law firm, which specialized in the quick extraction of disclosure settlements. ${ }^{8}$ Viewed in this sense, the only surprising thing of Chancery's latest shellacking of disclosure settlements was that it was so late in arriving. Perhaps for this reason, Trulia was widely hailed by commentators as the elimination of a "deal tax" that imperiled acquisitions and dampened shareholder gains.

In this paper, we offer a contrarian response to the triumphalism that has surrounded Trulia since its publication. We argue that the plausible economic consequences of prohibition are complicated-far more so than meets the eye. It is far from clear that disclosure-only settlements systematically hurt target shareholders, nor is it clear that prohibiting (or otherwise restricting) such settlements helps. In fact, we advance the thesis that in many plausible situations, discouraging disclosure-only settlements can actually hurt target shareholders. To the extent that courts wish to embrace a default rule about such practices, there may be plausible reasons to set that default dial at the permissive end of the scale when it comes to disclosure settlements.

The kernel of our argument flows from three simple propositions. First, we assert that an important (indeed paramount) goal of corporate law in the M\&A context is to maximize the target-company shareholders' ex ante welfare - e.g., by facilitating value-enhancing deals, increasing premia, and maximizing overall expected value. Consequently, if tolerating certain low-value / speculative MOLs somehow furthered this objective (for whatever reason), then so doing would be justifiable on policy grounds. ${ }^{9}$ Second, we show

\footnotetext{
${ }^{6} 129$ A.3d 884 (Del. Ch., January 22, 2016)

${ }^{7}$ See CornerstoneResearch (2018) (documenting an approximate 20 percentage point reduction between 2014 and 2017 ).

${ }^{8}$ See Friedlander (2016).

${ }^{9}$ To be sure, one could take issue with this desideratum on first principles; but the underlying shareholder primacy objective has remained (and will likely continue to remain) sacrosanct in conventional corporate law and finance. If one were instead beholden to the policy objective of eliminating nuisance suits (subordinating other policy objectives), prohibiting disclosure settlements might be a good way to do it.
} 
that judicial scrutiny of peppercorn settlements operates to reduce attorneys' ex ante incentives to file and then develop legal challenges to announced acquisitions. While some of the foreclosed litigation would no doubt culminate in disclosure settlements of little value to shareholders, other foreclosed matters could well die on the vine as well, deemed unworthy of pursuit by a profit-maximizing plaintiff bar. This dampening effect on plaintiff attorney incentives, can remove the threat of outside monitoring faced by buyers, target management, advisers, boards, and the like. In the end, we show that even if prohibiting peppercorns were hugely effective at stemming attorney-shareholder agency costs, it may come at the cost of exacerbating others, generating costs that can plausibly swamp the benefits.

We identify several plausible consequences of prohibiting peppercorn settlements. They include the following:

1. It may become less lucrative for plaintiff attorneys to search for and develop potentially legitimate cases where the deal price appears suspiciously low. Even for the litigation that still occurs, the plaintiff attorney's expected payoff shrinks, thereby reducing her ex ante incentives to file / investigate. ${ }^{10}$

2. Anticipating a lower sensitivity of litigation exposure to the deal price, target managers may attempt to extract - and acquirers may be willing to pay - larger managerial side payments (i.e, private benefits), in substitution for a lower transaction price.

3. M\&A negotiators may even have a perverse incentive to push down the deal terms further still, with the inferior terms acting as a type of "house money" to underwrite top-up settlements entailing financial concessions in addition to disclosures, thereby manipulating judicial scrutiny of disclosure settlements. But because such top-up settlements (a) occur only probabilistically after a deal (see point 1 above), and (b) are net of attorney fees, shareholders would be worse off with such adjustments than if they simply received more attractive deal terms up front.

4. Faced with increased total costs (more side payments and larger settlements), some potential acquirers may be discouraged from pursuing certain deals. As a result, value-enhancing takeovers that would have otherwise occurred can be rationed out of the market.

5. Since fewer cases settle early, more of the remaining cases will proceed to the later stages of the litigation process, with some of them possibly resulting in an injunction. Consequently, the rate of injunctions could increase.

To illustrate our argument, we develop a theoretical framework of merger negotiations and ensuing MOLs to study the plausible economic effects of disclosure settlements (and the desirability of constraining them judicially). In our model, multiple strategic players with divergent interests interact, including buyers, target managers, target shareholders, and plaintiff attorneys. Misaligned incentives pervade these relationships, including those of the plaintiff attorney, who wishes to maximize her negotiated fee from the defendant and consequently favors peppercorn settlements conveying minimal (if any) value to shareholders. Although courts can potentially "fix" the attorney-shareholder agency problem by forcing settlements to apportion a proportional monetary share of value to shareholders, we demonstrate that under plausible parametric conditions, this fix can actually be worse than the disease itself: I.e., restricting peppercorn settlements could lead to reduced deal premia, reduced takeover probabilities, and reduced expected target shareholder value (as measured ex ante). Viewed in this light, the desirability of the recent move of Delaware courts to

\footnotetext{
${ }^{10} \mathrm{Cf}$. Friedlander (2016). Once a plaintiff attorney commits to developing a case, of course, she may well work harder after Trulia to uncover non-disclosure oriented claims; but her ex ante payoff will still tend to fall.
} 
deter/prohibit disclosure settlements is unclear, at least if one evaluates that doctrinal repositioning through the lens of shareholder welfare.

It is important to emphasize that our key message in this paper is not necessarily to endorse disclosureonly settlements categorically. Rather, our aim is more modest: we simply argue the policy-making terrain here is complicated, and that one must make full sense of it conceptually in order to appreciate its collateral consequences. So doing helps clarify what empirical indicia are (and are not) helpful in diagnosing whether MOLs and disclosure settlements represent a problem that requires fixing. In this light, our model delivers predictions that are related to broader empirical implications of the Trulia decision-implications that we briefly explore empirically. Specifically, a key result of our model (Proposition 4) predicts that expected shareholder welfare will increase (controlling for other factors) upon a Trulia-like shock only if acquisition prices / premia also increase in equilibrium after the shock. We test this necessary condition empirically, using data from announced public-company acquisitions both before and after Trulia. Using foreign-incorporated targets as a control group, we find that the doctrinal shock of Trulia is - at best - associated with a statistically insignificant increase in target-company premia on average, and for our most plausible specifications the effect appears to be the opposite. (Although we ultimately view these empirical results as indistinguishable from zero they stand in marked contrast with the increased prices / premia we would expect to observe if Trulia had conveyed considerable value on target shareholder welfare.

Several caveats to our analysis deserve mention before proceeding. First, our argument is (naturally) confined to disclosure settlements of plenary MOLs, but that scope of attention may actually understate the case. There may be several close-by alternatives to disclosure settlements that would render prohibition ineffective. For example, if a plaintiff attorney files a lawsuit seeking additional disclosures and the defendant immediately capitulates by making the sought-for disclosures, the plaintiff attorney may still be able to procure a fee award, asserting that her facially legitimate demands were mooted (resulting in a corporate benefit). The recent Delaware decisions give a wide berth to "mootness" fee applications (even permitting them to be negotiated with little judicial second guessing ${ }^{11}$ ). Alternatively, shareholders may also have an option of filing an appraisal action. Appraisal actions frequently settle as well, though the general rule is that such actions are in the appraisal plaintiff's private interests, and not for the common benefit of shareholders as a whole. Consequently, attorney fees are disfavored in such actions. On the other hand, once a plaintiff establishes standing, appraisal proceedings impose no explicit burden of proof on the parties, leaving it to the judge to assess fair value. To the extent that judicial scrutiny of disclosure settlements induces substitution into these alternatives, the complications of prohibition may be even stronger than we advertise here.

Second, our analysis highlights an interesting and difficult quandary in how best to understand and manage the dialogue between researchers, policy makers, and legal participants. While we believe such dialogue to be helpful and constructive, it is also important to keep in mind the stage of development of (and academic consensus about) research propositions that might be used to inform legal policy. In the case of MOLs, various actors may have inadvertently fed one another's enthusiastic condemnation of the practice, resulting in a type of echo chamber that quickly catalyzed a major doctrinal reform. That legal reform may yet prove beneficial. Perhaps it will not. But in any event, the case against disclosure settlements is (from our perspective) nowhere near as overpowering as portrayed in the rhetoric that initially spawned — and later impelled - the doctrinal sea change. Viewed in this light, one might argue that the doctrinal shift was premature. That said, the very sea change that Trulia represents also proves extraordinarily helpful in program evaluation. Much can be learned from the effects of a sudden shock that induces reactions among rational, strategic players. The fact that we are able to use the shock to test implications of our model reveals

${ }^{11}$ See Trulia, 129 A.3d at 897-8. 
an additional benefit of such shocks as a form of jurisprudential experimentation ${ }^{12}$

Finally, our contribution here is substantially (though not entirely) a critical one, questioning a specific doctrinal change that has recently swept over MOL jurisprudence. We do not endeavor at length to take on the larger, "if we were king" question: i.e., might some other reform proposal dominate both the traditional status quo ante and the new quasi-prohibition under Trulia? Although we reserve much of that task for future work, we also observe that an effective "generic" solution for agency problems is to sell the productive asset to the agent, causing her to internalize all relevant trade-offs. For managerial agency costs, such asset transfers may not be practicable due to managers' wealth constraints and risk preferences. MOLs, however, may be different: Auctioning (or "spinning off") the MOL to outside attorney-bidders - with auction proceeds distributed to shareholders and ensuing damages/settlement retained by the purchasing attorney - may be a far more effective approach for protecting shareholder value and reducing M\&A related agency costs. At present, the recent doctrinal reforms combined with the procedural rules governing representative actions ${ }^{13}$ would appear to make such a transfer difficult to pull off. To the extent one is interested in larger structural reforms, however, an MOL auction process deserves some consideration. ${ }^{14}$

Our analysis proceeds as follows. Section 2 offers a brief overview of the institutional structure of mergerrelated shareholder litigation, tracing the recent case law regarding disclosure settlements. Section 3 sets out a theoretical framework of M\&A negotiations followed by prospective shareholder litigation. There we analyze the effects of imposing judicial scrutiny of disclosure settlements - which we model as requiring a prescribed minimal threshold of value that must go to the shareholder-plaintiffs (rather than their attorneys) from a settlement. Section 3.3 characterizes the (unique) equilibrium that comes from our framework, exploring how litigation activity, deal incidence, deal pricing and overall shareholder welfare interact in equilibrium. Section 4 harnesses these equilibrium insights to generate predictions of how several welfare-relevant measures of interest (e.g., deal price, deal incidence, and expected shareholder welfare) plausibly change as one increases judicial scrutiny of peppercorn settlements. There we show that under relatively weak conditions, all three may decrease even as the settlement incentives of plaintiff attorneys and their clients become aligned. Section 6 discusses extensions and robustness of our argument, as well as positing empirical measures by which we calibrate an optimal legal rule. Section 6 concludes. A technical Appendix offers more detailed derivations of our results in the main text.

\section{MOL Structure, Process and Settlement}

As should be clear, our analytical argument draws heavily on understanding how MOL litigation affects a variety of cross-cutting agency relationships. Consequently, to motivate that enterprise we must first sketch out (at a relatively high level) some of the core institutional contours of MOLs, as well as their plausible relationship to settlement procedures, fee awards, case selection, and acquisition structuring. This section proceeds along those lines, with emphasis on the recent judicial skepticism of fee award requests.

As is well known, public company acquisitions can be complicated. They are usually the end product of

\footnotetext{
${ }^{12}$ Indeed, this paper uses Trulia as a type of "field experiment" that facilitates better understanding of how judicial policy interacts with private incentives. Such field experimentation may well be desirable in complex financial markets settings. See, e.g., Spitzer and Talley (2014).

${ }^{13}$ See, e.g., Del. Chancery Court Rule 23(aa) and Rule 23.1(b) (prohibiting parties from receiving compensation in return for serving as representative plaintiffs).

${ }^{14}$ Indeed, the canonical disclosure settlement sort of mimics this structure (sans the auction proceeds), with the attorney receiving $100 \%$ of the monetary compensation and the plaintiff class receiving (largely meaningless) peppercorn. The new scrutiny of disclosure settlements under Trulia has the effect of pushing us away from (and not towards) the auction solution. (We acknowledge - but cabin - the question of whether an auction process for the MOL might itself be susceptible to agency costs, suboptimal pricing, and ensuing shareholder litigation.) For more on equity-financing of representative litigation, see Issacharoff (2014).
} 
long and painstaking processes of valuation, auction design, due diligence, negotiation, and tax structuring (to name a few); and even after a deal is signed, it may take many months to receive the shareholder approvals necessary to close it. During that tenuous time between signing and closing, of course, a variety of hazards lurk, including unforeseen circumstances and market fluctuations that can materially affect both the synergies from the deal and the underlying division of surplus.

During the last fifteen years, shareholder litigation has been one such hazard awaiting those who attempt to navigate the aforementioned shoals. It is not uncommon for one (or more) plaintiff attorneys to issue press releases within hours of a deal's public disclosure, announcing an investigation into possible breaches of fiduciary duty related to the merger. While not legal filings, such releases often serve as vehicles for client recruitment, with an actual complaint ensuing typically within a week or two of the announced deal - frequently even in advance of the proxy materials describing the precise terms of the transaction. Most MOLs are brought as direct class actions in state court, allowing them to skirt the enhanced procedural and pleading hurdles that attend either shareholder state derivative actions or federal actions (where pleading standards are typically higher). Complaints usually feature a host of allegations, including standard fiduciary duty claims, "Revlon" claims, aiding and abetting allegations, and a variety of disclosure infirmities. They usually seek to enjoin the merger from going forward. ${ }^{15}$ In many cases, multiple MOLs are filed, sometimes in different states (though multi-forum litigation may be decreasing somewhat due to Delaware's 2015 embrace of forum selection charter provisions).

A key strategic moment in a typical MOL occurs when the plaintiff moves for a preliminary injunction motion, a factor that bears significantly on settlement dynamics. First, when filed by the plaintiff to enjoin a deal (as is typical), such motions afford plaintiffs some ability to obtain discovery on an expedited basis - a process that Delaware courts have largely routinized. ${ }^{16}$ Second, should the injunction issue, the plaintiff enjoys considerable bargaining leverage, allowing her to hold up a deal's closing until the injunction is lifted (e.g., through a settlement). Such hold-up threats can be particularly costly to both transacting parties (especially the target). If the injunction is denied, in contrast, some measure of negotiation leverage swings back to the defendant, who now has the option of putting the litigation on the back burner until the closing of the deal. ${ }^{17}$ Injunctions in this context can also be challenging to predict: Ordinarily, such preliminary orders are difficult to procure, because plaintiffs must be able to demonstrate not only a likelihood of success on the ultimate merits of their claim, but also "irreparable harm" if the injunction is not issued. While these elements are designed to favor defendants, the M\&A context presents peculiar countervailing challenges when it comes to irreparable harm: for it is difficult at best (and impossible at worst) to unwind a closed merger after the fact (particularly for a public company target), and damages computation is often fraught with hazards and measurement error. Both factors plausibly weigh heavily on many a judge's mind when contemplating a denial of the injunction. ${ }^{18}$ This ambivalence is arguably redoubled when the underlying complaint alleges disclosure infirmities, making it more difficult to retrace how (or whether) additional disclosures might have altered shareholder votes had the injunction issued.

Given the manifest risks and uncertainties in the process, it is not uncommon for the parties to engage in

\footnotetext{
${ }^{15}$ For some types of claims (such as Revlon claims), pre-closing injunctive relief may be the only relief available. Compare Corwin v. KKR Financial Holdings LLC, 125 A.3d 304 (Del. 2015) (Revlon scrutiny does not apply to post-closing damages claims) to In re Saba Software, Inc. Stockholder Litigation (C.A. No. 10697-VCS) (Del. Ch,. 2017) (Revlon may survive to post-closing damages claims if shareholder approval involves defective disclosure or preclusive tactics).

${ }^{16}$ See Court of Chancery Guidelines for Expedited Discovery in Advance of a Preliminary Injunction Hearing, available at http://courts.state.de.us/chancery/docs/PIDiscoveryGuidelines.pdf.

${ }^{17}$ In reality, the incentive to settle still remains strong, particularly if D\&O insurance excludes coverage for various allegations in the underlying complaint.

${ }^{18}$ This one-way ratchet phenomenon is arguably reflected in the astonishing frequency with which M\&A attorneys employ a variety of no-going-back aphorisms, such as "You can't put the genie back in the bottle," "You can't un-ring the bell," and (our personal favorite) "You can't put the toothpaste back in the tube."
} 
active settlement negotiations early on - sometimes even before the court rules on the preliminary motion. Such negotiations also take place in the shadow of what will likely transpire should the case proceed to litigation. In that case, fee awards for plaintiff attorneys are commonplace, and are granted under the "common fund" doctrine. Some jurisdictions base fees on (so-called) "lodestar" methods (effectively an hourly rate) or "percentage of the fund" assessments (which acts as a tax on the total dollar settlement amount / judgment). Delaware uses a hybrid approach. Several factors (sometimes known as the Sugarland ${ }^{19}$ factors) come into play in assessing attorney compensation, including: ${ }^{20}$

1. The results achieved;

2. The time and effort of counsel;

3. The relative complexities of the litigation;

4. Any contingency factor; and

5. The standing and ability of counsel involved.

When a case generates a monetary settlement / judgment award, these factors naturally work into a fee award for the plaintiff attorney. In settlements, this fee award is typically agreed upon by the parties (though the defendant has the ability to contest an award demanded by the plaintiff). Delaware courts compensate the plaintiff attorneys with a contingency percentage of the monetary recovery that scales up (and down) with the extent of the benefit of the attorney's efforts. The exact percentage varies, but tends to scale up depending how "deep" the case went into the litigation process. The top of the range appears to be around $33 \%$ for cases that culminate in a very late stage settlement. The percentage falls for cases that have settled long in advance of trial. Thus, when a case settles extremely early, typical awards are in the range of 10-15\% of the monetary benefit conferred. When cases settle somewhere in the middle (e.g., after plaintiffs have engaged in meaningful litigation efforts, several depositions and some motion practice), typical fee awards hover in the Goldiloxian range of $15-25 \%$. Ultimately, the award is left open to judicial discretion. ${ }^{21}$

When a settlement is non-monetary, in contrast (such as a disclosure or amendment settlement), percentage fee awards are untenable, and the lodestar approach is the only remaining option. In many such cases, moreover, the settling parties still typically present the court with a negotiated agreement the attorney's fee, both attesting that the fee is fair and reasonable, and leaving a court with little (if any) manifest opposition. Although the underlying Sugarland factors remain in play in such situations, ${ }^{22}$ the lack of contestation can make it tempting for a court to sign off. ${ }^{23}$ That said, starting in around 2009, the courts began to wonder aloud about the propriety of fee awards in disclosure-only settlements, which alter neither the price nor the terms of the underlying deal. Although such settlements generally still were approved, the opinions began consistently to float questions about whether the additional disclosures are material — or even helpful - to shareholders. Vice Chancellor Glasscock's ruminations on this score from 2011 are typical:

There is a risk in any disclosure-only settlement that both the plaintiffs and the defendants have agreed to trivial disclosures as the path of least resistance to a desired end: for the defendants, the release of claims without significant cost, and for the plaintiffs, access to fees and costs. It is proper, therefore, for this Court to scrutinize disclosure-only settlements, both substantively and to determine whether the plaintiffs' efforts have conferred a benefit on the class. ${ }^{24}$

\footnotetext{
${ }^{19}$ Sugarland Indus., Inc. v. Thomas, 420 A.2d 142, at 149-50 (Del.1980).

${ }^{20}$ See Amer. Mining Corp. v. Theriault, 51 A.3d 1213, at1254 (Del. 2012).

${ }^{21}$ Amer. Mining Corp. v. Theriault, 51 A.3d 1213, at 1259-61.

${ }^{22}$ See, e.g., In re PAETEC Holding Corp. S'holders Litig., C.A. No. 6761-VGC, at 14-15 (Del. Ch. Mar. 19, 2013).

${ }^{23}$ See, e.g., In re. Sauer-Danfoss Inc. S'holders Litig., 2011 WL 2519210, at 18 (Del. Ch. Apr. 2011).

${ }^{24}$ In re. Sauer-Danfoss Inc. S'holders Litig., 2011 WL 2519210, at 17 (Del. Ch. Apr. 2011).
} 
Two years later, in an unpublished bench opinion in $2013,{ }^{25}$ then-Chancellor Strine rejected a disclosure settlement, noting that nearly $100 \%$ of the shareholders voted to approve the proposed deal (after the additional disclosures were made), and questioning whether the additional disclosures "would have been meaningful, would have been interesting, in any real way to someone voting on this transaction[.]" Ultimately, Chancellor Strine dismissed the case based on class certification grounds, which (along with the unpublished nature of the opinion) left open whether and to what extent Delaware judges would be willing to reject such settlements in the future, and with what degree of regularity.

We did not have to wait long to find an answer. Beginning in the fall of 2015, several Chancery Court opinions began to lower the boom on disclosure-only settlements, resulting in the current status quo (where they are either heavily disfavored or functionally prohibited). In In re Riverbed Tech Shareholders Litigation, ${ }^{26}$ Vice Chancellor Glasscock expressed serious doubts about the value of a prescribed disclosure to shareholders, causing him to whittle down the plaintiff attorney fee request to $\$ 329,000$. The Court took particular note of the multiple layers of agency-cost problem inherent with with MOLs:

Such cases are particularly fraught with questions of agency: among others, the basic questions regarding the behavior of the fiduciaries that are the subject of the litigation; questions of metaagency involving the adequacy of the actions of the class representative - the plaintiff - on behalf of the class; and what might be termed meta-meta-agency questions involving the motivations of counsel for the class representative in prosecuting the litigation. At each remove, there may be interests of the agent that diverge from that of the principals. This matter, involving the deceptively straightforward review of a proposed settlement, bears a full load of such freight. (p. 2)

Shortly thereafter, in In Re Aruba Networks SH Litigation, ${ }^{27}$ Vice Chancellor Laster joined the fray through an unpublished transcript opinion, refusing to sign off on a disclosure settlement packaged with a $\$ 387,500$ attorneys' fee award, refusing as well to certify the class based on inadequacy of representation. Although the parties attested to the fair and reasonable nature of the settlement, Laster was unconvinced, writing "We have to acknowledge that settling for disclosure only and giving the type of expansive release that has been given has created a real systemic problem. We've all talked about it now for a couple years. It's not new to anybody. But when you get the sue-on-every-deal phenomenon and the cases-as-inventory phenomenon, it is a problem. It is a systemic problem" (p. 65). ${ }^{28}$

In early 2016, the decision that would prove to be the most durable and visible blow to disclosure settlements finally emerged in In re Trulia, Inc. Stockholder Litigation, ${ }^{29}$ a case that concerned Zillow, Inc.'s announced acquisition of Trulia in a stock-for-stock merger valued at approximately $\$ 3$ billion. Plaintiffs had alleged that Trulia's directors had breached their fiduciary duties in a variety of ways in approving the proposed merger on unfair terms. Four months after filing, the litigants reached a preliminary settlement under which Trulia would supplement its proxy materials so as to give shareholders additional (and purportedly more complete) information. In exchange, the plaintiff stockholders agreed to drop their preliminary

\footnotetext{
${ }^{25}$ Transatlantic Holdings Inc. Shareholders Litigation, Case No. 6574-CS (2013).

${ }^{26} 2015$ WL 5458041 (Vice Chancellor Glasscock) (September 17, 2015).

${ }^{27}$ CA 10765 (Vice Chancellor Laster) (Oct. 9. 2015).

${ }^{28}$ After dismissing the case outright, Laster left a final parting shot:
}

I have just compensated you with lengthy disclosure about this case, so you've gotten now what you got for the class. I would not personally give you any more. It may not be disclosure you like, just like a lot of times, when I get objections from class members, they look at the disclosure that you guys got for them and say, "What is this about? We don't need this. This is not helpful at all." You probably don't think what I've told you is helpful at all. That's fine. But you've had the benefit of disclosure. (pp. 74-75).

${ }^{29} 129$ A.3d 884 (2016) (Del. Ch. January 22, 2016) 
injunction motion and provide broad release of claims, including "unknown claims" and claims "arising under federal, state, foreign, statutory, regulatory, common law or other law or rule." Finally, the parties proposed $\$ 375,000$ fee for plaintiffs' counsel.

The additional disclosures that the parties stipulated to constitute the settlement came in four categories, but most of them essentially dealt with adding more granularity to the valuation analysis that was disclosed to shareholders: (1) certain synergy numbers in J.P. Morgan's valuation analysis; (2) selected comparable transaction multiples; (3) selected public trading multiples; and (4) implied terminal EBITDA multiples for a relative discounted cash flow analysis (p. 900).

Chancellor Bouchard found these additional disclosures to be of questionable value, writing:

[U]nder Delaware law, when the board relies on the advice of a financial advisor in making a decision that requires stockholder action, those stockholders are entitled to receive in the proxy statement "a fair summary of the substantive work performed by the investment bankers upon whose advice the recommendations of their board as to how to vote on a merger or tender rely." This "fair summary" standard has been a guiding principle for this Court in considering proxy disclosures concerning the work of financial advisors for more than a decade." ... A fair summary, however, is a summary. By definition, it need not contain all information underlying the financial advisor's opinion or contained in its report to the board". In my view, disclosures that provide extraneous details do not contribute to a fair summary and do not add value for stockholders. (p. 28)

Concluding that the disclosures in this case constituted extraneous details (and little more), the Chancellor disallowed the settlement, taking the time to issue an ominous warning to future litigants about a heightened materiality standard disclosure settlements:

$[T]$ o the extent that litigants continue to pursue disclosure settlements, they can expect that the Court will be increasingly vigilant in scrutinizing the "give" and the "get" of such settlements to ensure that they are genuinely fair and reasonable to the absent class members. ( $\mathrm{p}$. 2)...."[P]ractitioners should expect that disclosure settlements are likely to be met with continued disfavor in the future unless the supplemental disclosures address a plainly material misrepresentation or omission, and the subject matter of the proposed release is narrowly circumscribed to encompass nothing more than disclosure claims and fiduciary duty claims concerning the sale process, if the record shows that such claims have been investigated sufficiently. In using the term 'plainly material,' I mean that it should not be a close call that the supplemental information is material as that term is defined under Delaware law." (p. 10, emphasis added).

In many practitioners' minds, In re Trulia drove a significant nail into the coffin of disclosure settlements in Delaware, erecting a judicial standard - "plain materiality" - that many predict will prove prohibitively difficult to satisfy in practice. ${ }^{30}$ In our view, this characterization rings true (even if the current case law leaves the door slightly ajar for other species of disclosure settlement. ${ }^{31}$ Perhaps a better route for litigants

\footnotetext{
${ }^{30}$ It should be noted that Delaware's new posture towards disclosure settlements-while noteworthy in its challenge to plaintiffs - is not the most demanding. For example, Texas Rule of Civil Procedure 42(i)(2) requires that "If any portion of the benefits recovered for the class are in the form of coupons or other noncash common benefits, the attorney fees awarded in the action must be in cash and noncash amounts in the same proportion as the recovery for the class." See Tex. Civ. Prac. \& Rem.Code $\S \S 26.001$ (a) \& 26.003. Texas courts have invoked this rule to deny attorney fees to class counsel in a disclosure-only case. Kazman v. Frontier Oil Corp. 398 S.W.3d 377 (14th Dist. 2013); Rocker v. Centex Corp., 377 S.W.3d 907 (Tex. App. 2012).

${ }^{31}$ As noted in the Introduction, there may be other ways to characterize what is essentially a disclosure settlement in different garb as a mootness settlement. If the defendant voluntarily makes the additional requested disclosures, then the plaintiff may
} 
going forward in seeking judicial approval of a settlement is simply to avoid the "pure-form" disclosure settlement altogether. That is, in addition to whatever additional disclosures may be prescribed (if any), a settlement can likely sidestep Trulia by prescribing either real price adjustments or amendments to deal terms. Although such substantive deal restructuring may be easier said than done (and it is far harder to pull off than simply making additional disclosures), we note that it was a relatively common settlement provision not long ago. And moreover, savvy counter-parties to the M\&A transaction can prospectively facilitate judicial clearance if - as we predict below - they deliberately leave some surplus on the table during deal structuring to serve as a type of "house money" for settlement concessions, thereby either sidestepping Trulia or satisfying its materiality standard. Whether this strategic response (or others) to Trulia scrutiny is ultimately good, bad, or indifferent for shareholders is far from obvious, requiring a more systematic economic analysis. It is to this analysis we turn in the next Section.

\section{A Model of Mergers, MOLs, and Settlement}

This section develops a game-theoretic model of merger negotiations, consummation, and ensuing litigation, highlighting the interaction of two agency problems. The first problem concerns the corporate manager, whose incentives to negotiate the terms of the acquisition may conflict with shareholder welfare. The second concerns the plaintiff's attorney, whose incentives to settle also may conflict with shareholder interests. The core idea behind the model is that these two incentive problems are intertwined, and thus attempts to mitigate one may exacerbate the other.

\subsection{Players, Information and Bargaining}

Our analytical framework centers on a business enterprise (the "target"), which is held by a large number of identical shareholders who value it at $\hat{p} \geq 0$ (the target's going concern value). The target is randomly matched with a buyer ${ }^{32}$ with valuation $v$, where $v$ is distributed ex ante according to a commonly known distribution function ${ }^{33} F_{v}(v)$ on $\mathbb{R}^{+}$.

An acquisition is efficient whenever $v>\hat{p}$; and, when this is the case, the price that maximizes shareholder welfare is $p=v$. The deal, however, is negotiated by the target's manager, not the shareholders (though shareholder approval is required at a later stage, analyzed momentarily). The manager has no equity interest in the target but derives a private benefit of control $\psi>0$, which she loses if the target is acquired, and thus she will negotiate an acquisition only if she can extract a side-payment $b \geq \psi$ from the buyer. ${ }^{34}$ This gives

declare the case moot, while seeking a fee award based on the "common benefit" of forcing the disclosure. While defendants can still (in theory) contest the attorney fee award, they may have an incentive to go along. Moreover, the "plainly material" standard announced in Trulia apparently does not apply in a mootness case. A February 2016 Delaware decision, for example, found that a lower standard applies for fee awards in moot cases. Louisiana Municipal Police Employees' Retirement System v. Black, C.A. 9410-VCN (Del. Ch. Feb. 19, 2016). Alternatively, a second way to obtain a fee for only supplemental disclosures is to resolve the dispute privately, with a stipulation of dismissal with prejudice only as to the named plaintiff, notice to the stockholders and a negotiated fee. Such an approach is expressly permitted under Trulia.

${ }^{32}$ We represent the target's management as a unitary player. We merge boards and executive officers into a single strategic player so as to concentrate on the (many) other pertinent strategic interactions. We conjecture that our basic points would easily generalize into this richer context (even if boards and CEOs have interests that are not perfectly aligned). We also represent the buyer and the attorney as unitary players.

${ }^{33}$ We will denote all density functions by a small $f$ accompanied by the appropriate subscript.

${ }^{34}$ We merge boards and executive officers into a single strategic player so as to concentrate on the (many) other pertinent strategic interactions. We conjecture that our basic points would easily generalize into this richer context (even if boards and CEOs have interests that are not perfectly aligned). We also represent the buyer and the attorney as unitary players. The model is robust to the introduction of a manager's equity interest in the target as long as the manager is not the sole proprietor. We model the side payment as being in cash so that the benefit to the manager equals the cost to the buyer, but our framework is general enough to consider in-kind compensation (e.g., employment at the surviving entity), which may introduce a distinction between the benefit to the manager and the cost to the buyer of providing that benefit. 
rise to the first conflict of interest: the manager has incentives to negotiate a deal price $p<v$ so that she can extract a greater side payment $b$, and she may decide to forego potentially efficient deals when the private benefit fails to offset the loss of control, that is, if $b<\psi$. The manager's pursuit of self-interest will typically reduce both deal prices and deal frequency below the values that maximize shareholder welfare.

In the event an acquisition is signed up (but before it is voted on by the shareholders), the target is randomly matched with a plaintiff attorney of type $k$, where $k$ is drawn from $F_{k}(k)$ on $\mathbb{R}^{+}$. As described below, the value of $k$ captures the attorney's private effort costs of pursuing litigation. (For example, more able attorneys and those with more familiarity with the industry will tend to bear lower costs, in the form of lower $k$.) Since the attorney earns only a portion of the settlement while bearing most of the costs of litigation, her incentives to file, settle or litigate will not be perfectly aligned with those of shareholders, creating the second key conflict of interest.

If a trial eventuates, both sides are assumed to bear additional litigation costs of $c>0$, and a court ${ }^{35}$ reviews the fairness of the deal price in relation to its own assessment of a "fair" price, $p^{*}$, which is randomly distributed around the "best price" shareholders could obtain, $v$ (namely, it is distributed according to $F_{p^{*}}\left(p^{*}\right)$ on $\mathbb{R}$ with $\left.\mathrm{E}\left(p^{*}\right)=v\right) .{ }^{36}$ If $p^{*}>p$, then the court enjoins the deal and shifts the plaintiff's litigation fee $c$ to the defendant; if instead $p^{*} \leq p$, then the court rules for the defendant with no fee shifting. ${ }^{37}$ The court must also mechanically approve any settlement between the parties, in a manner specified below.

All active players (the manager, the buyer and the plaintiff attorney) are fully informed and hence deal negotiations and settlement negotiations occur under complete information. In contrast, the shareholders and the court only observe $p$ and the terms of settlement; hence they cannot directly police the initial deal or settlement process. ${ }^{38}$ This asymmetry of information is the source of the two agency problems introduced above. We assign bargaining power so as to accentuate both agency problems: in deal negotiations with the prospective buyer, the manager has all the bargaining power; and in settlement negotiations with the buyer-defendant, the attorney has all the bargaining power. In both cases, the party with bargaining power makes a take-it-or-leave-it (TIOLI) offer to the buyer. ${ }^{39}$

\subsection{Sequence and Policy Parameters}

The strategic interaction among the players unfolds over six stages (with no discounting) as illustrated by Figure 1 and summarized below. (Dashed arrows indicate out of equilibrium outcomes.)

Stage 1 (policy-making). A policy maker establishes attorney compensation rules, $\tau$ and $\sigma$, representing the respective shares of a settlement amount that must go to shareholders should the case settle early and late. (The attorney receives the remaining fractions $1-\tau$ of early settlements and $1-\sigma$ of late

\footnotetext{
${ }^{35}$ The court is the sole non-strategic actor in our framework-i.e., a "neutral referee" that mechanically applies the legal standard. Note also that, depending its distribution, $p^{*}$ might take negative values. This is immaterial for the analysis as the only values of $p^{*}$ that will be relevant for litigation and settlement outcomes are positive values of $p^{*}$.

${ }^{36}$ More precisely, $p^{*}=v+\varepsilon$, where the term $\varepsilon$ represents an unbiased noise component, which is distributed according to $F_{\varepsilon}(\varepsilon)$ on $\mathbb{R}$ with $\mathrm{E}(\varepsilon)=0$, and hence $F_{p^{*}}\left(p^{*}\right) \equiv F_{\varepsilon}\left(p^{*}-v\right)$ with the characteristics illustrated in the text.

${ }^{37}$ The asymmetry in fee-shifting follows current law. The model is robust to other court outcomes that do not enjoin the acquisition, such as damages or mere delay.

${ }^{38}$ This feature greatly simplifies the analysis without much loss of generality. What is crucial is that the agents (the manager and the attorney) have more information than the principal (the shareholders).

${ }^{39}$ In the large literature on settlement, failure to settle is generally attributed to either asymmetric information or divergent priors. In our model, litigants have the same information and hold the same priors about the probability of winning at trial. Settlement fails because the litigants can externalize some of the costs of going to trial on a passive, uninformed party, the shareholders, who do not participate in settlement negotiations. Considering asymmetric information or divergent priors would add a second or third reason not to settle and greatly complicate the analysis without tangible analytical gains. For a detailed overview of extant modeling approaches see Daughety and Reinganum (2012).
} 


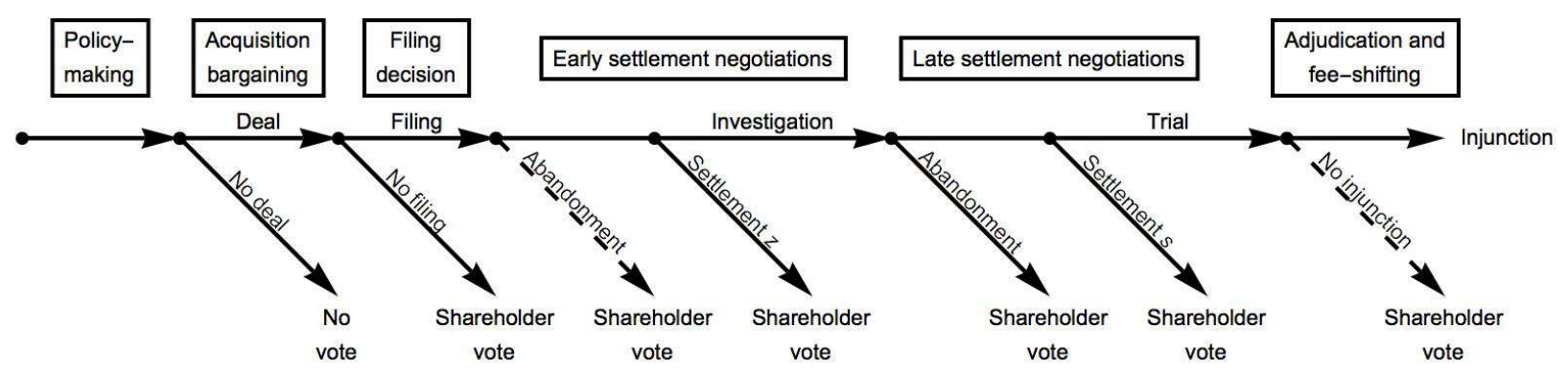

Figure 1: Timing of the game

settlements. ${ }^{40}$ ) As developed below, we conceive of Trulia as having raised the value of $\tau$ (the "Trulia parameter").

Stage 2 (acquisition bargaining). The manager makes a TIOLI offer $(p, b)$ to a randomly matched buyer of type $v$. Rejection ends the game.

Stage 3 (filing decision). If the buyer accepts the manager's offer, a randomly matched attorney $k$ examines the deal and may recruit a shareholder to serve as named plaintiff in a lawsuit. The attorney who files a complaint incurs an effort cost $\phi k{ }^{41}$

Stage 4 (early settlement negotiations). After filing, but before the attorney investigates the case, the attorney makes a TIOLI settlement offer $t$ to the buyer. If the parties settle, then shareholders vote on the deal with an adjusted price of $p+\tau t$. If the parties fail to settle, the attorney may either drop the case (and a vote for shareholder approval of the original terms $p$ follows) or proceed to investigate it and gather evidence at a cost $k{ }^{42}$

Stage 5 (late settlement negotiations). If the attorney investigates the case, she learns the applicable legal standard $p^{*}$ and reveals it to the buyer. ${ }^{43}$ With this new information, the parties negotiate a late settlement, with the attorney once again making a TIOLI offer $s$ to the defendant. If the parties settle, then shareholders vote on the adjusted merger terms, $p+\sigma s$. If the parties fail to settle, the attorney may either drop the case (and shareholders vote immediately whether to accept the original terms, $p$ ), or proceed to trial at a cost $c$ (the court fee) for both parties.

Stage 6 (adjudication and fee-shifting): At trial, if $p<p^{*}$ then the court enjoins the merger and awards the plaintiff attorney her court fee of $c$ and a lawyer's fee proportional to the estimated harm prevented by the injunction: ${ }^{44}(1-\sigma)\left(p^{*}-p\right)$. If instead the deal price satisfies the legal standard $\left(p \geq p^{*}\right)$,

\footnotetext{
${ }^{40}$ More precisely, $\tau$ and $\sigma$ are the minimal shareholder shares. However, since settlement negotiations occur between the defendant and the plaintiff attorney, the actual shares emerging in equilibrium will be equal to these minimal shares. To avoid unnecessary derivations, we refer directly to these two parameters as the actual shareholder shares in the early and late settlements.

${ }^{41}$ Since the representative shareholder has nothing to lose and possibly something to gain from the litigation, we assume that she accepts with attorney's offer with certainty and do not discuss this issue further. In addition, since most of the effort will typically go into investigation at stage 4 , it is plausible to assume that $0<\phi<1$.

42 The total of stage- 3 filing and stage- 4 investigation costs is thus $(1+\phi) k$.

${ }^{43}$ Since, in the model, it will be a dominant strategy in equilibrium for the attorney to reveal $p^{*}$ to the buyer, we do not discuss alternative scenarios.

${ }^{44}$ Note that this setup allows us to capture the fact that the attorney's fee and hence the buyer's exposure to litigation depend on how the acquisition price $p$ compares to the court assessment $p^{*}$. A higher price $p$ paid upfront reduces both the probability and the costs of an injunction for the buyer. An alternative justification for making the attorney's fees decrease in $p$ is that a higher $p$ might make it more costly for the attorney to gather evidence supporting the claim that $p^{*}<p$, so that the net fee pocketed by the attorney decreases. While this is an important ingredient of our analysis, the specific functional form of the attorney's fee does not drive our qualitative results. Our chosen formulation has the virtue of simplifying calculations.
} 
the merger is submitted to the shareholders for approval, in which case each litigating parties (the defendant and the plaintiff's attorney) pay their own court fee $c{ }^{45}$

Shareholder approval at stages 3 to 6: At various stages in the game, shareholders are called upon to approve the proposed merger, as illustrated by Figure 1. In the Appendix, we show that it is optimal for the manager to offer a deal price $p \geq \hat{p}$ at stage 2, which guarantees shareholder approval at all stages of the game. ${ }^{46}$

\subsection{Litigation and Settlement}

As is standard practice, we solve the model backwards in time (starting at stage 6).

\subsubsection{Adjudication and late settlement}

At trial (stage 6), the court rules for the defendant if the court's estimate of the fair price is less than the deal price, $p^{*} \leq p$, and enjoins the deal if $p^{*}>p$. The plaintiff attorney and the buyer-defendant learn $p^{*}$ at the late settlement stage (stage 5 ) and hence anticipate the trial outcome. If $p^{*} \leq p$, the attorney has no credible threat to go to trial and finds it optimal to drop the case, so that the merger goes through at no additional costs. If instead $p>p^{*}$ and the attorney wishes to settle, she will make a TIOLI offer to the buyer equal to the highest amount the buyer is willing to pay to avoid litigation: ${ }^{47}$

$$
s=v-p-b+2 c+(1-\sigma)\left(p^{*}-p\right)
$$

where the first three terms $(v-p-b)$ capture the buyer's gross value from closing and the last two terms are the total court fees $(2 c)$ and the attorney's litigation compensation $(1-\sigma)\left(p^{*}-p\right)$. Even though bargaining occurs with complete information, settlement may (inefficiently) fail because a portion of the settlement amount must be paid to the shareholders. ${ }^{48}$ Thus, the attorney might deliberately sabotage a settlement if payoff from it, or $(1-\sigma) s$, falls short of her payoff from litigation, or $(1-\sigma)\left(p^{*}-p\right)$. Settlement is therefore feasible only if $s \geq p^{*}-p$, or equivalently if $p^{*} \leq \bar{p}$, where: ${ }^{49}$

$$
\bar{p} \equiv p+\frac{v-p-b+2 c}{\sigma}
$$

The cutoff value $\bar{p}$ represents the late settlement threshold. Table 1 summarizes the late settlement and litigation outcomes. Prior to discovering the applicable legal standard $p^{*}$ at stage 5 , the litigants' expected continuation payoffs are $\alpha$ for the attorney and $\beta$ the buyer, where:

$$
\begin{aligned}
\alpha & \equiv \int_{p}^{\bar{p}}(1-\sigma) s d F_{p^{*}}\left(p^{*}\right)+\int_{\bar{p}}^{\infty}(1-\sigma)\left(p^{*}-p\right) d F_{p^{*}}\left(p^{*}\right) \\
\beta & \equiv \int_{-\infty}^{p}(v-p-b) d F_{p^{*}}\left(p^{*}\right)-\int_{p}^{\infty}\left(2 c+(1-\sigma)\left(p^{*}-p\right)\right) d F_{p^{*}}\left(p^{*}\right)
\end{aligned}
$$

\footnotetext{
${ }^{45}$ Note that the attorney, not the shareholders, bears the court fee if the court rules for the defendant.

${ }^{46}$ The manager and the buyer could theoretically lower the nominal deal price $p$ below $\hat{p}$ with the expectation that a settlement would bring the total price pocketed by the shareholders above $\hat{p}$. However, with deal prices below $\hat{p}$, the attorney's agreement to the settlement becomes a necessary condition for a subsequent shareholder approval, which gives the attorney an anomalous power to veto such deals, resulting in higher total costs for the manager and the buyer.

${ }^{47}$ Note that we suppress the arguments of the various functions that we introduce in order to keep notation at a minimum. We add explicatory notes at various points of the analysis to avoid possible confusion.

${ }^{48}$ The model is robust to allowing the manager to take part in the late settlement negotiations. The result is an increase in the likelihood of settlement due to the fact that the manager, who loses her private benefit $b$ if the merger is enjoined, can renounce part of this benefit to make settlement more attractive to the attorney and hence more likely. All other results remain substantially unchanged. See note 39 for additional considerations on settlement failure.

${ }^{49}$ Note that, at the equilibrium, $\bar{p}>p$ because $v \geq p+b$, that is, because the total price paid by the buyer at the acquisition stage must be less than the buyer's value or the buyer would not have accepted the manager's offer.
} 


\begin{tabular}{c||c|c|c|} 
& $\begin{array}{c}p^{*} \leq p \\
\text { Abandonment }\end{array}$ & $\begin{array}{c}p<p^{*} \leq \bar{p} \\
\text { Late settlement, } s\end{array}$ & $\begin{array}{c}p^{*}>\bar{p} \\
\text { Litigation/Injunction }\end{array}$ \\
\hline \hline Buyer-defendant & $v-p-b$ & $v-p-b-s$ & $-2 c-(1-\sigma)\left(p^{*}-p\right)$ \\
\hline Plaintiff attorney & 0 & $(1-\sigma) s$ & $(1-\sigma)\left(p^{*}-p\right)$ \\
\cline { 2 - 4 }
\end{tabular}

Table 1: Continuation payoffs at the late settlement stage (stage 5)

which will be key determinants of the decision to settle early considered next. ${ }^{50}$

\subsubsection{Early settlement and filing}

At stage 4, prior to investigating the case (at cost $k$ ) and learning $p^{*}$, the attorney can attempt to settle. If $k \geq \alpha$, the attorney cannot credibly threaten to sue and investigate, and she thus must abandon. If $k<\alpha$, however, the attorney makes a TIOLI early settlement offer to the buyer equal to

$$
t=v-p-b-\beta=\int_{p}^{\infty} s d F_{p^{*}}\left(p^{*}\right)
$$

which fully captures the buyer's value of avoiding further proceedings. If the buyer refuses the settle, the game continues as above and the attorney earns $\alpha-k$ in expectation. As before, since the attorney receives only a fraction $1-\tau$ of the early settlement, settlement is feasible if $t \geq \frac{\alpha-k}{1-\tau}$, that is, if $k \geq \underline{k}$ and fails otherwise, where

$$
\underline{k} \equiv \alpha-(1-\tau) t<\alpha
$$

is the early settlement threshold. ${ }^{51}$ Moving back to the filing stage 3, the attorney decides to file a case if the filing cost $\phi k$ is less than her expected payoff. Table 2 illustrates the expected payoffs that different types of attorneys receive from filing: Note that the payoff of attorneys with type $k \geq \alpha$ is negative. Expecting

\begin{tabular}{c||c|c|c|} 
& $\begin{array}{c}k<\underline{k} \\
\text { Investigation }\end{array}$ & $\begin{array}{c}\underline{k} \leq k<\alpha \\
\text { Early settlement, } t\end{array}$ & $\begin{array}{c}k \geq \alpha \\
\text { Abandonment }\end{array}$ \\
\hline \hline Plaintiff attorney & $\alpha-(1+\phi) k$ & $(1-\tau) t-\phi k$ & $-\phi k$ \\
\cline { 2 - 4 } & &
\end{tabular}

Table 2: Attorney's expected payoff from filing (stage 3)

that they will abandon after filing, these attorneys never file the case in the first place. Even when $k<\alpha$, however, the attorney finds it advantageous to file a suit only if the filing costs are less than her expected returns from filing. We define in Lemma 2 a filing threshold $\bar{k}$ that can take three different values. ${ }^{52}$

$$
\bar{k}=\left\{\begin{array}{lll}
\frac{\alpha}{1+\phi} & \text { if } \quad \tau>1-\frac{\phi}{1+\phi} \frac{\alpha}{t} \\
\frac{(1-\tau) t}{\phi} & \text { if } & 1-\phi \frac{\alpha}{t} \leq \tau<1-\frac{\phi}{1+\phi} \frac{\alpha}{t} \\
\alpha & \text { if } & 1-\frac{\alpha}{t} \leq \tau<1-\phi \frac{\alpha}{t}
\end{array}\right.
$$

Table 3 characterizes the attorney's decision to file, settle early or proceed to later stages (where she may abandon the case, settle late or proceed to trial). In addition to this general case, which obtains for intermediate values of the Trulia parameter $\left(1-\frac{\alpha}{t} \leq \tau<1-\frac{\phi}{1+\phi} \frac{\alpha}{t}\right)$, there are two degenerate cases in

\footnotetext{
${ }^{50}$ Note that the buyer's continuation payoff $\beta$ has only two addenda because, by the definition of $s$, we have $v-p-b-s=$ $-2 c-(1-\sigma)\left(p^{*}-p\right)$.

${ }^{51}$ Note that $t>\alpha$ because at the early settlement stage the attorney is able to capture the value of payment that the defendant would have to make to the shareholders if settlement occurred later.

${ }^{52}$ Recall that $\alpha$ and $t$ are not functions of $\tau$ and $\phi$. Moreover, note that $\alpha>\frac{(1-\tau) t}{\phi}>\alpha-(1-\tau) t \geq \frac{\alpha}{1+\phi}$ in their relevant domains.
} 
which the early settlement threshold $\underline{k}$ is inoperative. If $\tau$ is sufficiently low $\left(\tau<1-\frac{\alpha}{t}\right)$ the early settlement threshold is negative $(\underline{k}<0)$; hence all filed cases are settled early. If, instead, $\tau$ is sufficiently large $\left(\tau \geq 1-\frac{\phi}{1+\phi} \frac{\alpha}{t}\right)$, then the early settlement threshold is greater than the filing threshold $(\underline{k}>\bar{k})$ and thus no filed case will ever settle early. ${ }^{53}$ Figure 2 illustrates all possible cases: The shaded area corresponds to the

\begin{tabular}{c||c|c|c|}
\multicolumn{1}{|c||}{} & $p^{*} \leq p$ & $p<p^{*} \leq \bar{p}$ & $p^{*}>\bar{p}$ \\
\hline \hline$k \geq \bar{k}$ & \multicolumn{3}{|c|}{ No filing } \\
\hline$\underline{k} \leq k<\bar{k}$ & \multicolumn{3}{|c|}{ Early settlement } \\
\hline \multicolumn{1}{c||}{$k<\underline{k}$} & Late abandonment & Late settlement & Injunction \\
\cline { 2 - 4 }
\end{tabular}

Table 3: Filing, settlement and litigation

case embedded in Table 3, while the regions to the left and to the right of it capture the two degenerate cases just described. Figure 2 also visualizes the direct effects of a change in the Trulia parameter $\tau$ on litigation outcomes and shows that an increase in $\tau$ reduces early settlements in two ways: It pushes some cases past the early settlement stage - the reason is that the early settlement is "taxed" more as $\tau$ increases - and discourages filing - the intuition is that the attorneys who refrain from filing as $\tau$ increases are those who would have settled earlier. Changes in $\tau$, however, also affect deal prices, which in turn have a feedback effect on litigation outcomes. We turn to this problem in the following sections.

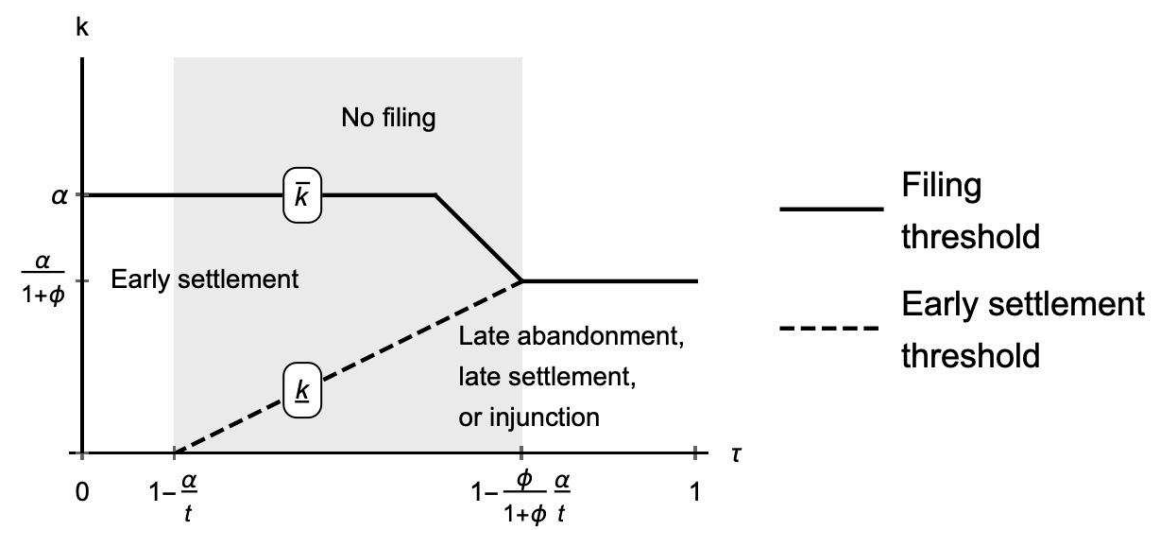

Figure 2: Litigation outcomes

\subsection{Acquisition}

With the litigation continuation game fully characterized, we now step back to analyze the negotiations between the manager and a randomly matched buyer of type $v$ (stage 2). ${ }^{54}$ Recall that the manager makes a TIOLI offer $(p, b)$, representing the price paid to the shareholders and the manager respectively. The manager sets this two-part price in order to maximize her expected payoff subject to (1) participation of the buyer-so

\footnotetext{
${ }^{53}$ Note that $0<1-\frac{\alpha}{t}<\frac{\phi}{1+\phi} \frac{\alpha}{t}<1$ (because $\alpha<t$ ) and hence all of the three cases are always relevant.

${ }^{54}$ Recall that the manager and the attorney observe $v$.
} 
that the buyer accepts the offer - and (2) approval by the shareholders: ${ }^{55}$

$$
\begin{aligned}
& \max _{(p, b)}[b-\psi-\gamma] \\
& \text { s.t. }(1): v-p-b-\lambda \geq 0 \\
& \text { s.t. }(2): p-\hat{p} \geq 0
\end{aligned}
$$

where $\lambda$ and $\gamma$ capture, respectively, the costs of exposure to litigation for the buyer and the manager, and recall that $\psi$ captures the private benefits of the manager (which she surrenders if the sale takes place). The buyer faces potential costs in stages 4 and 5 due to the possibility that the merger will be enjoined and its value lost, as well as the costs from early / late settlement payments incurred to avoid injunction. Since the buyer has no bargaining power during settlement negotiations, the buyer is indifferent between settling early and proceeding to the later stages, so that the early settlement amount $t$ captures the buyer's cost of facing a lawsuit irrespective of its outcome. Therefore, the buyer's exposure to litigation is simply equal to the early settlement amount $t$ times the probability to be matched with an attorney who will file a lawsuit, $F_{k}(\bar{k})$ (Appendix A.3 contains a detailed derivation):

$$
\lambda \equiv t F_{k}(\bar{k})
$$

The manager is indifferent to litigation ex post unless the deal is enjoined, in which case she loses the side-payment $b$ and regains private benefits $\psi$. Thus, the manager's expected cost from litigation is equal to the net private gain $(b-\psi)$ times the probability of an injunction. ${ }^{56}$

$$
\gamma \equiv F_{k}(\min \{\underline{k}, \bar{k}\})\left[1-F_{p^{*}}(\bar{p})\right](b-\psi)
$$

where $F_{k}(\min \{\underline{k}, \bar{k}\})$ is the probability that a case is filed and proceeds past the early settlement stage, and $\left[1-F_{p^{*}}(\bar{p})\right]$ is the probability that the case proceeds to trial in the late litigation stage. Note that $\gamma \leq b-\psi$ and the manager is willing to sell the company at any price so long as she can recoup the foregone private benefits of control, that is, if $b>\psi$. In the next section, we will investigate the welfare effects of policies that regulate the early settlement stage.

\section{Analysis}

In this section, we derive testable predictions concerning the welfare effects of "shocks" to the Trulia parameter, $\tau$, and in particular on the equilibrium deal price $p$ (and private benefit $b$ ), the frequency of deals, and litigation outcomes. In line with the descriptive account provided by Friedlander (2016), the model introduced above predicts an equilibrium partitioning (or "specialization") of the plaintiffs' bar into three distinct groups characterized by different litigation strategies, as illustrated in Figure 3: high-cost attorneys $(k \geq \alpha)$ never file; intermediate-cost attorneys $\left(\alpha \leq k<\frac{\alpha}{1+\phi}\right)$ file only to seek an early settlement; low-cost attorneys $(k<\alpha)$ file and may stick it through to late-stage litigation, settlement, or abandonment.

The status quo ante prior to Trulia is characterized by low $\tau$ (plausibly $\tau<1-\frac{\alpha}{t}$ ) with a very large

\footnotetext{
${ }^{55}$ The shareholders' constraint (2) follows from Lemma 1 (see Appendix), which shows that the manager will not deliberately "lowball" the shareholder consideration below their reservation price $\hat{p}$, even though shareholders could receive in excess of $\hat{p}$ after accounting for settlement. (In Section (A.1), we explain that the manager prefers to overcompensate shareholders in some states of the world in order to avoid even greater net payments to the plaintiff attorney.)

${ }^{56}$ The manager has an interest in preventing an injunction and would be willing to renounce to part of her benefit $b$ in order to facilitate settlement. As mentioned in note 48, this possibility would move the late settlement threshold $\bar{p}$ to the right making settlement more likely. This would not lower the buyer's costs (because the buyer in indifferent between settling late and litigating in equilibrium) and hence all other results would be substantially unchanged.
} 
number of lawsuits that settle early with high probability and with little or no value for shareholders. In this setting, Trulia can be interpreted as a policy intervention aimed at discouraging intermediate-cost attorneys from filing, thereby reducing the incidence of early settlements. Ideally, if the Trulia parameter were raised to $\tau>1-\frac{\phi}{1+\phi} \frac{\alpha}{t}$, Trulia would have accomplished its stated purpose of eradicating early settlements and rationing intermediate-cost attorneys out of the market (see Figure 3). Reducing or eradicating early settlements, however, also can affect pricing, which in turn affects shareholder and social welfare. To be true to Trulia, then, one must verify that "success" - as measured by reducing the rate of litigation followed by early settlement - also translates into greater welfare.

In what follows we shows that the type of litigation reduction intended by Trulia need not translate into welfare improvements, for several reasons. First, the reduction of early settlement comes at the cost of pushing more cases to the later stages of litigation, which are more costly per se. As Figure 3 illustrates, the attorneys who file and settle early at low levels of $\tau$ may rect differently to a change in the Trulia parameter. As $\tau$ increases, while intermediate-cost attorneys may refrain from filing, low-cost attorneys may file and proceed directly to the later stages of litigation. Second, the change can result in a reduction in shareholder welfare as measured by deal prices and deal frequency. That is, making it difficult for attorneys to recover reduces their incentives to monitor, which may exacerbate the other agency problem between shareholders and manager, which attorneys are supposed to keep in check.

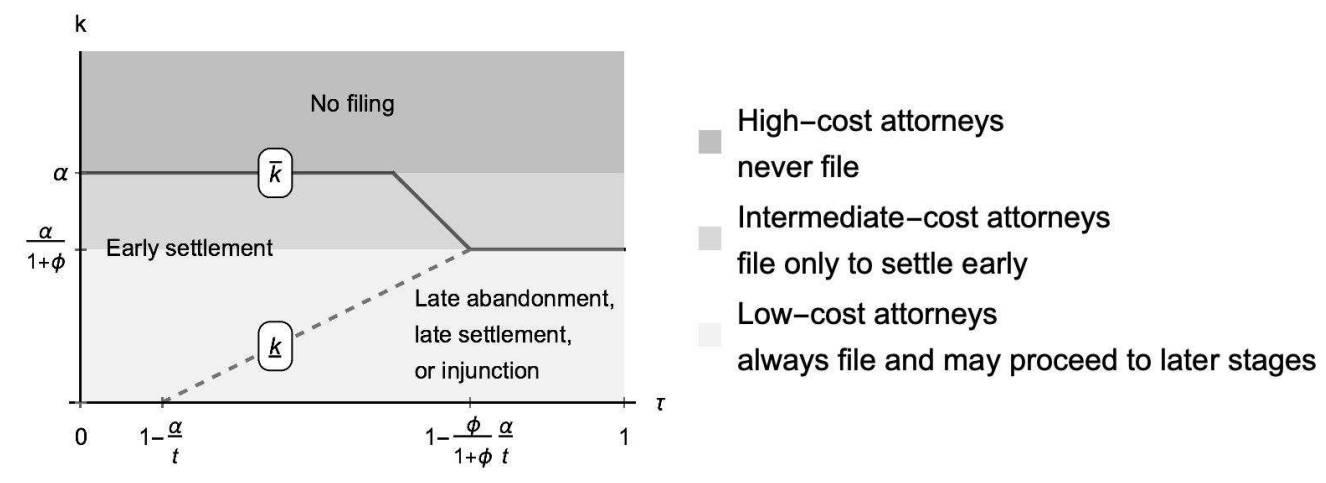

Figure 3: Law-firm specialization

\subsection{Deal prices}

The first welfare-related question we address is whether deal prices increase or decrease following a policy change affecting the fraction $\tau$ of the early settlement that is pocketed by the shareholders. In particular, we posit that the pre-Trulia value was close to $\tau=0$ so that the question is whether nudging $\tau$ upwards to some positive value will increase deal prices. To focus on the sharper scenario, we assume, without loss of generality, that $\psi=0$ so that (as it is easy to verify) all deals with positive expected value $(v>\hat{p})$ go through and the only question of interest is the price of such deals. Increasing $\tau$ makes early settlements more expensive for the defendant and hence increases the buyer's exposure to litigation. To compensate the attorney for a lower share $(1-\tau)$ in the early settlement, the buyer must increase the settlement amount $t$ or, if she fails to do so, she must accept that a larger share of cases will proceed to the next stage with additional costs.

On the one hand, increasing the deal price $p$ in response to an increase in $\tau$ reduces the buyer's later exposure, because a higher deal price $p$ makes it less likely that the court will find the price to be unfair and hence reduces both the likelihood and the costs of injunctions and late settlements. In turn, lower later costs 
have a beneficial effect on early settlements, pushing up deal prices. On the other hand, however, knowing that she will pay larger litigation and settlement costs later due to a greater value of $\tau$ might induce the buyer to reduce her costs today. Payments made during litigation are akin to delayed deal payments and, to the extent that the "tax" owed to the attorney is not too large, it might make sense for the buyer to substitute late for early payments, thereby reducing $p$. The next proposition shows that both outcomes are possible and delivers an indeterminacy result. The effect of a change in $\tau$ on deal prices depends on a complex interaction between the parameters of our model.

Proposition 1. An upward shock to the shareholders' share of early settlements, $\tau$ (the Trulia parameter), could increase, decrease or leave unchanged equilibrium deal prices, $p$.

Proof. The prove is by identification of example distribution functions and parameter values that generate either an increase or a decrease in deal price. More details are given in the Appendix.

We report below the results of two simulations pertaining to Proposition 1, which illustrate the result. As Figure 5 shows (and as is easy to verify formally), an increase in $\tau$ has no effect on deal prices in the extreme regions in Figure 2, where $\tau$ is close to 0 (that is, if $\tau<1-\frac{\alpha}{t}$ ) or close to 1 (that is, if $\tau \geq 1-\frac{\phi}{1+\phi} \frac{\alpha}{t}$ ). The reason is that $\tau$ does not affect the relevant thresholds in those regions.

Consider first a policy that brings $\tau$ from $\tau_{1}=0$ to $\tau_{2}=1$, so that the shock completely eradicates early settlements, the stated goal of Trulia. As a comparison of the two simulations in Figures 5a and 5b shows, the deal price can either increase or decrease as a result of the policy change. In particular, in simulating the results we varied the ability of the court to assess the value of the merger for the buyer. Do do so, we considered two different distributions of $p^{*}$ around the same value of $v$-which we set at 100 .

Compared to Figure 5a (simulation "price increase"), the simulation underlying Figure 5b (simulation "price decrease") features a less tight distribution of $p^{*}$-in fact, a mean-preserving spread on the initial distribution - that is, the court is better able to assess $v$, as depicted in Figure 4. In both simulations the

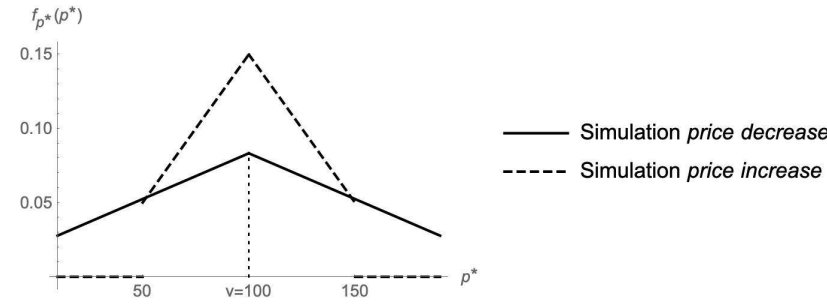

(a) Density function for $p^{*}$

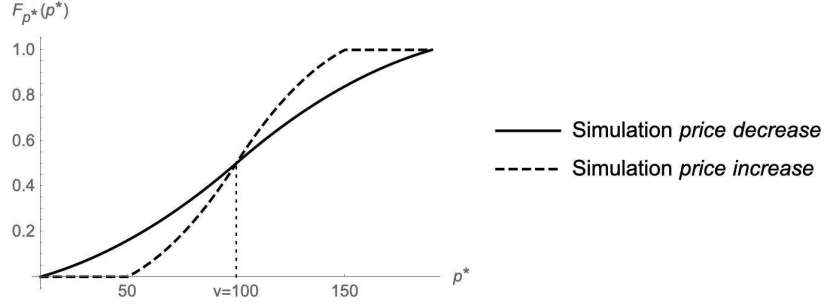

(b) Cumulative distribution function for $p^{*}$

Figure 4: Simulated distributions for $p^{*}$

equilibrium price is a relatively small fraction of firm value, $v$. This should not be surprising given that our setup maximizes conflicts of interests and hence allows the manager and the plaintiff attorney to capture most of the value of the merger either ex ante through side payments or ex post through settlement and litigation fees. In the simulation "price decrease", the equilibrium price goes from $22.8 \%$ of firm value when $\tau=0$ to $22 \%$ when $\tau$ is increased to 1 . In this case, eradicating early settlements causes a $3.6 \%$ drop in deal prices. In contrast, in the simulation "price increase", the price goes from $21.5 \%$ to $22,7 \%$ of firm value when $\tau$ is increased from 0 to 1 . Here there is a $5.6 \%$ increase in price. (The equilibrium side payment $b$ to the manager is around $60 \%$ of firm value in both simulations and is roughly constant. $)^{57}$

\footnotetext{
${ }^{57}$ Note that the equilibrium price in the simulation "price increase" does not fall in the range of values of $p$ that the court may consider fair. This implies that the court will necessarily enjoin the merger if the case goes to trial. Yet, by raising the price, the contracting parties can reduce the expected costs of such outcomes, including the settlement amounts.
} 
The intuition for this result is that if the court is better able to assess firm value- that is, if $p^{*}$ is more tightly distributed around $v$-increasing the deal price is a relatively effective way to reduce the costs of late litigation, which in turn are more salient if most (or all) of the filed cases go to trial. From a different perspective, when the court cannot police deal prices effectively, the most productive way to reduce total deal costs is to cut the ex ante price of the deal $p$. In contrast, when the court is relatively effective in screening deals ex post, the contracting parties can do better by reducing the ex post price of the deal (that is, overall litigation costs) by increasing $p$.

At one end of the spectrum (when $\tau=0$ ), if the price is dispersed around $v$ as in the simulation "price decrease", the long right-tale of the distribution makes litigated case more expensive from the manager's perspective because, for any given deal price $p$, there is a higher chance that the deal will be enjoined at trial and that large attorney fees will be due. This effects pushes prices up when early settlements are rampant and incorporate later expectations. (Compare deal prices at $\tau=0$ across the two simulations.)

At the other hand of the spectrum (when $\tau=1$ ), with no early settlements the price is an important determinant of total deal cost - which include settlements, injunctions and fees - and hence the price is higher when the court is better able to police it (that is, when $p^{*}$ is more tightly distributed around $v$ ). (Now compare prices at $\tau=1$ across the two simulations.)

Next, each of the simulations provides some insights on the marginal effects of Trulia in the intermediate region in Figure $2\left(1-\frac{\alpha}{t} \leq \tau<1-\frac{\phi}{1+\phi} \frac{\alpha}{t}\right)$. As the patterns clearly show, prices can fluctuate somewhat erratically as a result of a change in $\tau$, reflecting the complex balancing of ex ante versus ex post costs of the deal, thereby reinforcing our indeterminacy result. In particular, as $\tau$ increases, fewer cases are filed to be settled early, but of those cases that are filed, more proceed to later (and more expensive) stages.

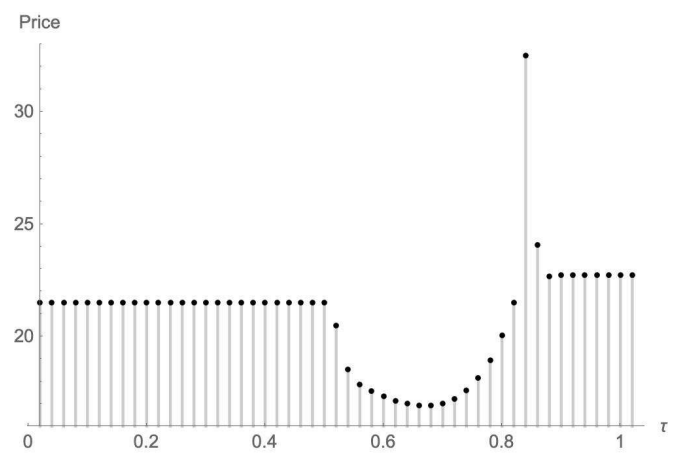

(a) Price increase

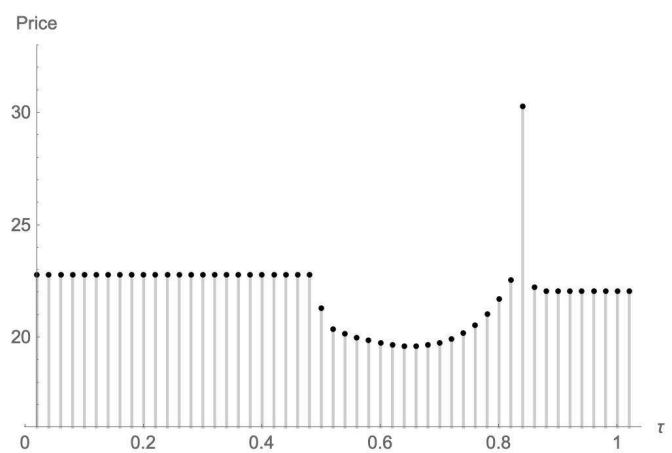

(b) Price decrease

Figure 5: Effects of Trulia on deal prices

\subsection{Deal frequency}

The closing of a deal depends on three players having a non-negative payoff: the manager, the buyer and the shareholders. Any solution to the constraint optimization problem in (1) satisfies the buyer constraint and the shareholders constraint by construction. Therefore, we can focus on the manager constraint. In the previous section we focused on the case with $\psi=0$. We relax this assumption now. Managers commonly enjoy private benefits of control they have to give up following a merger. The manager will be willing to negotiate a merger with the buyer if the net benefits from the deal offset the manager's foregone benefits of control, $b-\gamma>\phi$.

Proposition (2) shows that an increase in $\tau$ makes it less likely that the manager constraint is satisfied and 
hence suggests that deal frequency goes down as $\tau$ increases. The intuition is straightforward: an increase in $\tau$ adds a tax on closed deals - in the form of a larger payment to the shareholders in case of litigation - and hence discourages them.

Proposition 2. An increase in $\tau$ reduces deal frequency.

Proof. See Appendix.

\subsection{Shareholder welfare}

Shareholder welfare is affected by two factors. First, conditional on a deal closing, shareholder welfare increases in deal price. Since we have shown that an increase in $\tau$ might either increase or reduce deal prices, the effect of policies that increase $\tau$ on the welfare of shareholder conditional on deals being closed is ambiguous. In addition, we have seen that an increase in $\tau$ reduces deal frequency and hence deprives shareholders of potential deals. This second effect adds to the ambiguity noted above. Even if the price per deal increases, shareholders might still lose out because fewer deals (and possibly no deals) are closed.

Proposition 3. An increase in $\tau$ increases expected shareholder welfare only if accompanied by an increase in equilibrium price $p$.

Proof. Omitted.

Although Proposition 3 is in some ways trivial, it delivers a critical necessary condition for our empirical investigation. In particular, it makes clear that an upward shock to $\tau$ is only in shareholders' interests to the extent that it delivers an increase in equilibrium deal price. This necessary condition is, moreover, testable using empirical data - a task we turn to in the next section of this paper.

\subsection{Judicial outcomes}

Finally, changes in $\tau$ affect judicial outcomes both directly and through the effect they have on the equilibrium values of $p$ and $b$. As Figure 2 shows, a discontinuous change from $\tau_{\text {low }}<1-\frac{\alpha}{t}$ to $\tau_{\text {high }} \geq 1-\frac{\phi}{1+\phi} \frac{\alpha}{t}$ has the effect of eradicating early settlements, reducing filing and pushing more cases to the later litigation stages. Conditional on reaching that stage, however, cases may result in an injunction more or less often depending on the effects of $\tau$ on $p$ and $b$, which in turn affects the late settlement threshold $\bar{p}$. In the intermediate region, a marginal change in $\tau$ has similarly ambiguous effects.

Proposition 4. An increase in $\tau$ has an ambiguous effect on litigation outcomes. However, a large increase in $\tau$ from $\tau_{\text {low }}<1-\frac{\alpha}{t}$ to $\tau_{\text {high }} \geq 1-\frac{\phi}{1+\phi} \frac{\alpha}{t}$ eradicates early settlements.

Proof. Omitted.

\section{$5 \quad$ Empirical Implications}

Within our analytic framework, the Trulia opinion can be understood as introducing an upward shock in the legal policy variable $\tau$, defined as the minimal fraction of any "early settlement" amount that must be paid to the plaintiff class (rather than claimed as attorneys fees by the plaintiff attorney). Under this interpretation, the status quo ante prior to Trulia effectively fixed $\tau_{0}=0$, such that the plaintiff's attorney could effectively claim the entire monetary value of an early settlement, bargaining for peppercorn disclosures from the defendant. The release of Chancellor Bouchard's opinion, however, introduced an incremental upward shock to 
$\tau_{1}>\tau_{0}=0$, so that some meaningful value from the settlement must go to the shareholder class. As shown in Proposition 3, a necessary (but not sufficient) condition for such a shock to enhance shareholder welfare (on average) is that would have to induce positive price movements in subsequent acquisitions. In this section we offer a brief empirical investigation of this hypothesis, using stock price premium data from negotiated merger transactions both before and after the Trulia opinion was released. We find that the Trulia shock does not appear to have resulted in discernibly higher premiums - and if anything it visited a slight decline relative to plausible control groups.

We utilize data from the Thompson-Reuters SDC Platinum database, focusing on public-company acquisitions (foreign and domestic) executed between January 2011 and December 2018, where the value of the transaction exceeded US $\$ 100 \mathrm{~m}$, and in which at least $50 \%$ of control was sought by the acquirer. We further limited our inquiry to targets for which one-day, one-week and four-week stock-price premia were available. This process led to a data set of 11,694 announced acquisitions, of which 6,896 involved foreign targets, 2,848 involved US-incorporated Delaware targets, and 1,950 involved US-incorporated Non-Delaware targets. (See Table 4). Overall, approximately thirty-eight percent of the full panel involves acquisitions that were announced after the Trulia decision was published. The relative imbalance of this panel-combined with the advent of several idiosyncratic years during the Financial Crisis, gives us some hesitation about parallel trends, particularly prior to 2011. Therefore we report below on two balanced panels around January 2016, the first spanning Jan. 2013- Dec. 2018 (a six-year window), and the second spanning July 2014 - June 2017 (a three year window). The estimates for the full panel (2011-18) are provided in the Appendix (and are qualitatively consistent).

\begin{tabular}{|cccc|c|}
\hline Year & Foreign Target & US (Del) & US (Non-Del) & Total \\
\hline 2011 & 860 & 392 & 287 & 1,539 \\
2012 & 731 & 330 & 203 & 1,264 \\
2013 & 628 & 308 & 219 & 1,155 \\
2014 & 857 & 384 & 243 & 1,484 \\
2015 & 1,066 & 423 & 292 & 1,781 \\
2016 & 902 & 328 & 212 & 1,442 \\
2017 & 884 & 334 & 218 & 1,436 \\
2018 & 968 & 349 & 276 & 1,593 \\
\hline Total & 6,896 & 2,848 & 1,950 & 11,694 \\
\hline
\end{tabular}
Data Source: Thompson Reuters SDC Platinum Database (Jan. 2011 - Dec. 2018)

Table 4: All Targets by Target Incorporation Jurisdiction

Table 5 summarizes several financial metrics associated with the targets in the dataset. Somewhat unsurprisingly, Delaware targets tend as a general matter to be the largest subsample as measured by transaction value and earnings, while Foreign targets are slightly larger (on average) as measured by enterprise value. Of particular interest for analysis are the various 1-day, 1-week and 4-week stock-price premia associated with the announced acquisition. We will be primarily interested in these values to gauge whether the Trulia decision induced any positive price movement for affected targets (the "treatment" group) relative to foreign controls. As can be seen from the summary table, the announcement premia (particularly the non-Delaware US targets) appear to be particularly high and erratic. More granular analysis of the premium data (unreported, but available from authors) confirms that the distribution is skewed right across all years for all jurisdictional sub-samples (particularly so for the non-Delaware US targets). To minimize outlier effects, we converted the announcement premia into the natural logarithm of the gross premium, confirming that the resulting distribution more closely resembles a Gaussian distribution for all sub-samples. ${ }^{58}$ (All regressions below will be reported in these metrics.) To test the key necessary condition proven in Proposition 4, we

\footnotetext{
${ }^{58}$ Gross premia reflect the per-share price acquisition price as a percentage of exceeds the highest closing stock price for the
} 


\begin{tabular}{|c|c|c|c|c|c|c|c|c|c|c|c|c|c|c|c|c|}
\hline & \multicolumn{4}{|c|}{ Full Sample } & \multicolumn{4}{|c|}{ Foreign Targets } & \multicolumn{4}{|c|}{ US Del Targets } & \multicolumn{4}{|c|}{ US Non-Del Targets } \\
\hline & $\mathrm{N}$ & Mean & Median & St.Dev & $\mathrm{N}$ & Mean & Median & St.Dev & $\mathrm{N}$ & Mean & Median & St.Dev & $\mathrm{N}$ & Mean & Median & St.Dev \\
\hline Transaction Value (\$mil) & 11,694 & 1495.9 & 350.0 & 5627.5 & 6,893 & 1003.8 & 292.1 & 4182.2 & 2,845 & 2241.6 & 500.0 & 6555.8 & 1,953 & 2148.3 & 470.0 & 7952.0 \\
\hline Enterprise Value (\$mil) & 8,527 & 13694.4 & 1820.2 & 250000.0 & 6,142 & 14048.4 & 1692.6 & 290000.0 & 1,350 & 13619.3 & 2678.0 & 54899.1 & 1,035 & 11692.3 & 2021.3 & 50973.3 \\
\hline Target EBITDA (\$mil) & 10,190 & 1083.4 & 208.7 & 3448.7 & 5,663 & 735.6 & 122.4 & 2559.1 & 2,726 & 1471.2 & 406.2 & 3861.9 & 1,799 & 1590.2 & 356.7 & 4827.5 \\
\hline Ln (Target EBITDA) & 9,229 & 5.520 & 5.590 & 1.870 & 5,010 & 5.110 & 5.090 & 1.840 & 2,499 & 6.110 & 6.160 & 1.690 & 1,718 & 5.840 & 5.970 & 1.920 \\
\hline Target Total Assets (\$mil) & 11,420 & 20666.9 & 2215.8 & 120000.0 & 6,725 & 14269.4 & 1584.1 & 76474.2 & 2,802 & 34575.9 & 3507.750 & 200000.0 & 1,890 & 22829.5 & 3194.6 & 75703.6 \\
\hline Ln (Target Total Assets) & 11,415 & 7.770 & 7.710 & 1.950 & 6,721 & 7.490 & 7.370 & 1.910 & 2,802 & 8.200 & 8.2 & 1.920 & 1,889 & 8.180 & 8.070 & 1.920 \\
\hline Target ROA (winsor $5 \%)$ & 10,190 & 0.100 & 0.100 & 0.080 & 5,663 & 0.090 & 0.080 & 0.080 & 2,726 & 0.120 & 0.110 & 0.080 & 1,799 & 0.110 & 0.110 & 0.090 \\
\hline 1 day premium $(\%)$ & 7,162 & 102.5 & 10.5 & 3526.4 & 5,124 & 71.8 & 6.9 & 2931.8 & 1,127 & 39.8 & 20.6 & 306.9 & 911 & 353.1 & 16.6 & 7019.8 \\
\hline 1 week premium (\%) & 7,165 & 107.9 & 11.9 & 3542.1 & 5,125 & 78.3 & 8.2 & 2951.9 & 1,126 & 40.9 & 22.0 & 309.5 & 914 & 356.0 & 17.5 & 7025.1 \\
\hline 4 week premium $(\%)$ & 7,157 & 98.3 & 14.2 & 3119.4 & 5,115 & 65.0 & 10.2 & 2211.5 & 1,129 & 42.2 & 24.1 & 292.4 & 913 & 353.9 & 19.5 & 6981.9 \\
\hline Ln (1 day Gross Premium) & 7,162 & 0.130 & 0.100 & 0.430 & 5,124 & 0.100 & 0.070 & 0.440 & 1,127 & 0.210 & 0.190 & 0.330 & 911 & 0.200 & 0.150 & 0.450 \\
\hline Ln (1 week Gross Premium) & 7,165 & 0.140 & 0.110 & 0.440 & 5,125 & 0.110 & 0.080 & 0.460 & 1,126 & 0.220 & 0.200 & 0.330 & 914 & 0.210 & 0.160 & 0.460 \\
\hline Ln (4 week Gross Premium) & 7,157 & 0.150 & 0.130 & 0.440 & 5,115 & 0.120 & 0.100 & 0.460 & 1,129 & 0.230 & 0.220 & 0.330 & 913 & 0.220 & 0.180 & 0.460 \\
\hline
\end{tabular}

Data Source: Thompson Reuters SDC Platinum Database (Jan. 2003-Feb. 2017)

Table 5: Summary statistics of target firms

analyze empirically the effects of Trulia on the premium offered to target shareholders in announced acquisitions. We identify the Trulia effect through a difference-in-differences specification, deeming the date of Trulia opinion's release as the "treatment" event for targets affected by the holding (relative to a control group that was not similarly affected by the opinion). Foreign-incorporated public targets seem an apt and logical control group, since they are not subject to "shocks" produced by Delaware law. And, quite obviously, Delaware firms would seem to be the most worthy candidate as a treatment group (at least on first blush). The third group of non-Delaware, US-incorporated firms is harder to classify for at least two reasons. First, the highly focal role that Delaware corporate law plays likely has a role on other US jurisdictions. Many nonDelaware state courts within the US tend to treat Delaware as a bellwether jurisdiction, frequently viewing its case law as persuasive authority for their own jurisprudence. It is therefore quite conceivable the Trulia decision had significant influence outside Delaware, where the outcomes of litigated cases are plausibly harder to predict (and thus settlements more likely to be approved by non-Delaware judges). ${ }^{59}$ Thus, under this view, non-Delaware US targets are logical inclusions in the treatment group. Second, all US-incorporated firms can be subjected to MOLs outside their state of incorporation. ${ }^{60}$ This adds to the case for pooling both the Delaware and non-Delaware US targets as part of a treatment group.

That said, we recognize that reasonable minds may differ about how to conceive of non-Delaware US targets, and we therefore present results for both two plausible demarcations of treatment and control groups:

\section{Baseline: TREATMENT =US Targets (Delaware + US Non-Del.); CONTROL = Non-US Targets}

\section{DE Only: TREATMENT $=$ Delaware Targets; CONTROL $=$ Non-US Targets}

We identify the effects of the Trulia decision against the following specification:

$$
\operatorname{Ln}\left(\text { GrossPremium }_{i, t}\right)=\Omega_{0} \cdot \text { Treatment }_{i}+\Omega_{1} \cdot \text { PostTrulia }_{t}+\Omega_{2} \cdot\left(\text { Treatment }_{i} \times \text { PostTrulia }_{t}\right)+\vec{\alpha} \cdot Z_{i, t}++\varepsilon_{i, t}
$$

where $\operatorname{Ln}\left(\right.$ GrossPremium $\left._{i, t}\right)$ is the natural log of the gross stock premium from the acquisition of target $i$ who receives a bid at time $t$, Treatment $t_{i}$ is a dummy variable taking on the value of 1 if target $i$ is in the treatment group (pursuant to the two cases above), PostTrulia $a_{t}$ is a dummy variable taking on the value of 1 if the acquisition is announced after the Trulia decision, Treatment ${ }_{i} \times$ PostTrulia $_{t}$ is the differencein-differences interaction variable, $t_{i, t}$ is a vector of financial control variables for target $i$, and $\varepsilon_{i, t}$ is an

target in the previous 1-day, 1-week or 4-week period. For example, if a target company had a one-week closing price high of $\$ 50$, and then received a bid of $\$ 55$, its 1 -week gross premium would be equal to $1.10=\frac{55}{50}$ and the logged gross premium would be $\ln (1.10)=0.0953$.

${ }^{59}$ Of course, to the extent that Trulia announced a procedural (rather than substantive) rule, out-of-state courts might feel less legally compelled to follow it on jurisdictional grounds (even for Delaware corporations).

${ }^{60}$ Although choice-of-form provisions are becoming increasingly popular today, they are rare among targets in our sample; consequently, even Delaware-incorporated targets might be 
error term. Under this specification $\Omega_{2}$ is our coefficient of interest, reflecting the degree to which the Trulia opinion was associated with an upward/downward shock to deal premia once the opinion was issued. Within the context of our model developed above, recall that a necessary condition for a positive welfare effect of the opinion would be a positive shock on premia (and thus $\Omega_{2}>0$ ).

Although we initially drew data from a long panel (dating back to 2011), the advent of the Financial Crisis introduced significant upheaval in M\&A markets. We thus introduce our main result using regressions that span a shorter window of three years before and after the Trulia opinion was released. These analyses are illustrated in the top and bottom panels in Table 6 below.

\begin{tabular}{|c|c|c|c|c|c|c|c|c|c|c|c|c|c|c|c|c|c|c|}
\hline & \multicolumn{6}{|c|}{ One Day Announcement Returns } & \multicolumn{6}{|c|}{ One Week Announcement Returns } & \multicolumn{6}{|c|}{ Four Week Announcement Returns } \\
\hline & [1] & [2] & {$[3]$} & [4] & {$[5]$} & [6] & [1] & [2] & {$[3]$} & [4] & {$[5]$} & [6] & [1] & [2] & {$[3]$} & [4] & [5] & [6] \\
\hline Treatment & $0.149 * * *$ & $\begin{array}{c}0.149^{* * * *} \\
(044)\end{array}$ & $\begin{array}{c}0.103^{* * *} \\
\end{array}$ & $0.100^{* * * *}$ & $\begin{array}{c}0.094^{* * *} \\
\end{array}$ & $\begin{array}{c}0.091 * * * \\
\end{array}$ & $0.148^{* * *}$ & $\begin{array}{c}0.149^{* * * *} \\
\end{array}$ & $0.105^{* * * *}$ & $0.101^{* * * *}$ & $0.095^{* *}$ & $\begin{array}{c}0.092^{* *} \\
\end{array}$ & $0.149^{* * * *}$ & $0.151^{* * * *}$ & $0.115^{* * *}$ & $0.111^{* * * *}$ & $\begin{array}{c}0.104^{* *} \\
\end{array}$ & $0.100^{* *}$ \\
\hline PostTrulia & $\begin{array}{c}(3.15) \\
0.097 * * *\end{array}$ & $\begin{array}{c}(2.94) \\
0.094 * *\end{array}$ & $\begin{array}{c}(3.42) \\
0.074 * * *\end{array}$ & $\begin{array}{c}(3.25) \\
0.075 * * *\end{array}$ & $(2.72)$ & $(2.68)$ & $\begin{array}{c}(2.80) \\
0.093 * *\end{array}$ & $\begin{array}{l}(2.63) \\
0.090^{*}\end{array}$ & $(3.07)$ & $\begin{array}{c}(2.95) \\
0.075 * * *\end{array}$ & (2.49) & $(2.43)$ & $\begin{array}{l}(3.05) \\
(0.0 * * *\end{array}$ & $\begin{array}{l}(2.85) \\
0.087 *\end{array}$ & $(2.99)$ & $(2.89)$ & (2.49) & $(2.41)$ \\
\hline & (2.90) & $(2.54)$ & $(3.47)$ & (3.24) & & & $(2.41)$ & $(2.12)$ & $0.0 / 4,25$ & $(2.89)$ & & & $0.090^{2}=28$ & $\begin{array}{l}0.087 * \\
(2.27)\end{array}$ & $0.076^{2 * * *}$ & $0.07 / 7.64)$ & & \\
\hline atment $x$ PostTrulia & -0.063 & -0.058 & -0.038 & -0.038 & -0.029 & -0.029 & -0.06 & -0.056 & -0.038 & -0.038 & -0.028 & -0.029 & -0.066 & -0.059 & -0.052 & -0.052 & -0.041 & -0.042 \\
\hline & $(-1.27)$ & $(-1.20)$ & $(-1.20)$ & $(-1.01)$ & $(-0.77)$ & $(-0.75)$ & $(-1.06)$ & $(-1.00)$ & $(-1.08)$ & $(-0.97)$ & $(-0.68)$ & $(-0.68)$ & $(-1.41)$ & $(-1.18)$ & $(-1.26)$ & $(-1.18)$ & $(-0.88)$ & $(-0.90)$ \\
\hline Ln(Target Assets) & & $-0.026^{* * *}$ & $-0.035^{* * *}$ & $-0.031 * * *$ & $-0.035 * * *$ & $-0.031 * * *$ & & $-0.030 * * *$ & $-0.037 * * *$ & $-0.033 * *$ & $-0.037 * * *$ & $-0.034 * * *$ & & $-0.033^{* * *}$ & $-0.041 * * *$ & $-0.036^{* * *}$ & $-0.041 * * *$ & $-0.037 * * *$ \\
\hline & & $(-4.12)$ & $(-3.90)$ & $(-3.06)$ & $(-3.49)$ & $(-2.96)$ & & $(-3.76)$ & $(-3.84)$ & $(-2.93)$ & $(-3.35)$ & $(-3.07)$ & & $(-4.45)$ & $(-3.90)$ & $(-3.26)$ & $(-3.46)$ & $(-3.23)$ \\
\hline Target ROA & & & -0.21 & -0.192 & -0.225 & -0.198 & & & -0.203 & -0.179 & -0.22 & -0.187 & & & -0.227 & -0.21 & -0.247 & -0.222 \\
\hline & & & $(-1.20)$ & $(-1.15)$ & $(-1.26)$ & $(-1.13)$ & & & $(-1.11)$ & $(-0.99)$ & $(-1.18)$ & $(-1.00)$ & & & $(-1.24)$ & $(-1.18)$ & $(-1.35)$ & $(-1.22)$ \\
\hline Percent Cash & & & $-0.001^{* * *}$ & $-0.001 * * *$ & $-0.001 * *$ & $-0.001 *$ & & & $-0.001^{* * *}$ & $-0.001^{*}$ & $-0.001^{*}$ & $-0.001 *$ & & & $-0.001 * * *$ & $-0.001 * * *$ & $-0.001 *$ & $-0.001^{*}$ \\
\hline & & & $(-3.23)$ & $(-2.64)$ & $(-2.52)$ & $(-2.24)$ & & & $(-3.00)$ & $(-2.20)$ & $(-1.98)$ & $(-2.09)$ & & & $(-3.10)$ & $(-2.74)$ & $(-2.07)$ & $(-2.28)$ \\
\hline Industry FEs & No & No & No & Yes & No & Yes & No & No & No & Yes & No & Yes & No & No & No & Yes & No & Yes \\
\hline Quarterly FEs & No & No & No & No & Yes & Yes & No & No & No & No & Yes & Yes & No & No & No & No & Yes & Yes \\
\hline & 0.023 & 0.034 & 0.042 & 0.047 & 0.053 & 0.058 & 0.021 & 0.036 & 0.044 & 0.05 & 0.056 & 0.062 & 0.02 & 0.038 & 0.048 & 0.054 & 0.059 & 0.065 \\
\hline & 5,542 & 5,424 & 3,449 & 3,449 & 3,449 & 3,449 & 5,536 & 5,419 & 3,453 & 3,453 & 3,453 & 3,453 & 5,529 & 5,412 & 3,442 & 3,442 & 3,442 & 3,442 \\
\hline
\end{tabular}

(a) Panel A: Treatment = All US Targets (Jan. 2013 - Dec. 2018)

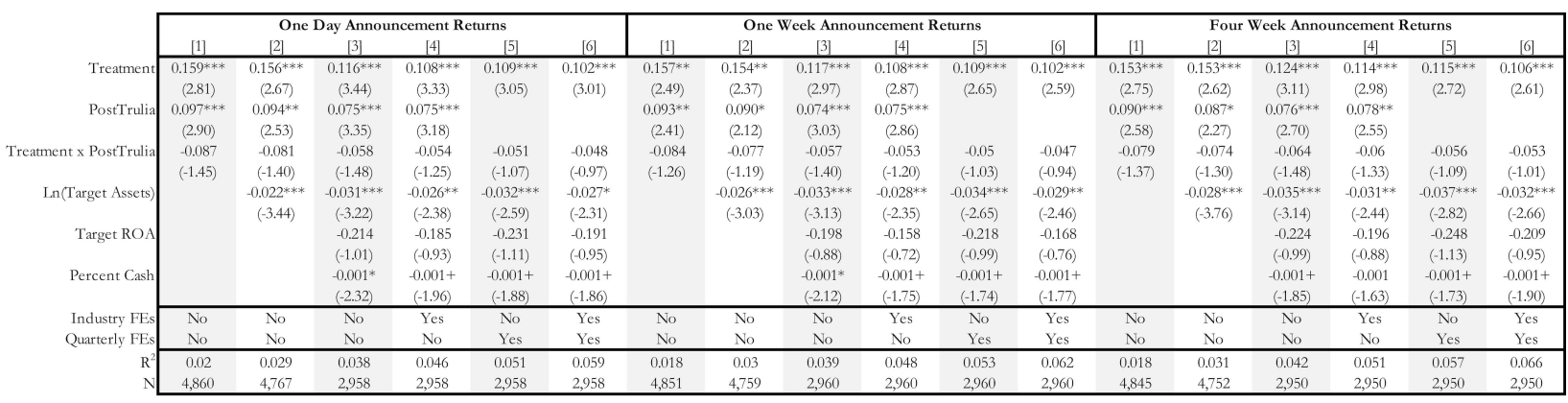

(b) Panel B: Treatment = Only Delaware Targets (Jan. 2013 - Dec. 2018)

Note: Each panel presents OLS estimations with industry- and year-clustered standard errors on several dependent variables corresponding to natural log of the 1-day, 1-week and 4-week gross stock price premium on announcement date, for public target acquisitions in excess of $\$ 100 \mathrm{~m}$ deal value where at least $50 \%$ of voting shares are sought. The January 2016 Trulia decision in the Delaware Chancery Court is the common treatment event, and the coefficient on the cross-product Treatment x PostTrulia is the diff-in-diff estimate. Foreign targets constitute the control group. Panel A reports estimates where all US targets are part of the treatment group, while Panel B drops non- Delaware US targets from the data set. Estimated t-statistics are in parentheses. Notation: $\left\{+,{ }^{*},{ }^{*},{ }^{* * *}\right\}$ denote significance at the $p=\{0.10,0.05,0.02,0.01\}$ levels $(2$-sided test). Data Source: Thompson Reuters SDC Platinum Database (Jan. 2013-Dec. 2018).

Table 6: Difference-in-Difference results

The two panels of Table 6 present our key baseline results, each exploring alternative specifications for different definitions of the control/treatment group, the stock premium measuring period, and the inclusion of various right-hand-side controls. (All regressions allow for permutations that include industry and quarter fixed effects, and all cluster standard errors across both year and industry). In all specifications, the differencein-differences coefficient $\left(\Omega_{2}\right)$ is consistently negative, though it is not precisely estimated and not statistically significant by conventional measures. Note, however, that the overall magnitude of the estimated coefficient is more extreme in Panel B (where only Delaware firms constitute the control group) relative to Panel A (where all US targets are the control group). The extent to which the effect of the Trulia opinion is attenuated in the control group may well signify reduced predictability of the opinion's reach outside of Delaware. The economic magnitude of the estimated effect varies, but appears to be somewhere in the neighborhood corresponding to 
about a quarter of a standard deviation in logged gross premia (or around a 1.2 percentage point difference in announcement premia).

Table 7 presents the same analysis as Table 6, but under an event window narrowed to 18 months before / after the Trulia opinion (July 2014 - June 2017). Once again, the estimated difference-in-differences coefficient remains consistently negative in all specifications, but it grows even stronger in economic magnitude and it becomes statistically significant in at least some specifications (without fixed effects added). And, as with Table 6, the slightly negative Trulia effect is most pronounced when non-Delaware US firms are excluded from the treatment group. In the Appendix, we present results of an identical set of regressions for the full sample (2011-18). The results differ only modestly from those above6: In the full sample, the Trulia opinion continues to be associated uniformly with a slight (but statistically insignificant) decrease increase in announcement premia somewhat more dampened than in either of the tables above. Taken together, we interpret these results as consistent with the view that Trulia induced either (a) no appreciable movement or (b) a slight downward shock in acquisition premia for treated firms. Even as a non-result, the implications

\begin{tabular}{|c|c|c|c|c|c|c|c|c|c|c|c|c|c|c|c|c|c|c|}
\hline & \multicolumn{6}{|c|}{ One Day Announcement Returns } & \multicolumn{6}{|c|}{ One Week Announcement Returns } & \multicolumn{6}{|c|}{ Four Week Announcement Returns } \\
\hline & [1] & [2] & [3] & [4] & {$[5]$} & [6] & [1] & [2] & [3] & [4] & {$[5]$} & [6] & [1] & [2] & [3] & [4] & [5] & [6] \\
\hline Treatment & $0.222 * * *$ & $0.223 * * *$ & $0.161 * * *$ & $0.154^{* * *}$ & $0.148^{* * * *}$ & $0.144 * * *$ & $0.226^{* * *}$ & $0.228 * * * *$ & $0.165^{* * *}$ & $0.158^{* * * *}$ & $0.151^{* * * *}$ & $0.146^{* * * *}$ & $0.221^{* * * *}$ & $0.225 * * *$ & $0.181^{* * *}$ & $\begin{array}{c}0.173^{* * * *} \\
(380)\end{array}$ & $0.167^{* * * *}$ & $0.161 * * *$ \\
\hline PostTrulia & $0.137^{* * * *}$ & $0.142 * * *$ & $0.114 * * *$ & $0.115^{* * * *}$ & & & $0.140^{* * * * *}$ & $0.144 * * *$ & $0.118^{* * * *}$ & $0.119^{* * * *}$ & & & $0.140^{* * * *}$ & $0.145^{* * * *}$ & $0.129 * * *$ & $0.131^{* * * *}$ & & \\
\hline & $(7.64)$ & $(9.30)$ & $(3.28)$ & (3.08) & & & $(7.18)$ & $(8.47)$ & (3.56) & $(3.22)$ & & & (7.24) & $(9.73)$ & $(4.63)$ & (3.75) & & \\
\hline eatment x PostTrulia & $-0.110 * * *$ & $-0.116 * * *$ & -0.071 & -0.068 & -0.055 & -0.053 & $-0.107 * * *$ & $-0.115^{* * * *}$ & -0.073 & -0.069 & -0.054 & -0.052 & $-0.111^{* * *}$ & $-0.114 * * *$ & $-0.088^{*}$ & $-0.085+$ & -0.071 & -0.069 \\
\hline & $(-2.97)$ & $(-3.76)$ & $(-1.36)$ & $(-1.22)$ & $(-0.97)$ & $(-0.91)$ & $(-2.70)$ & $(-3.37)$ & $(-1.48)$ & $(-1.33)$ & $(-0.94)$ & $(-0.88)$ & $(-4.30)$ & $(-4.54)$ & $(-2.02)$ & $(-1.84)$ & $(-1.39)$ & $(-1.33)$ \\
\hline $\operatorname{Ln}$ (Target Assets) & & $-0.020 * * *$ & $-0.027 * * *$ & $-0.023 * * *$ & $-0.027 * * *$ & $-0.024 * * *$ & & $-0.022^{* * *}$ & $-0.028 * * *$ & $-0.024 * * *$ & $-0.029 * * *$ & $-0.025 * * *$ & & $-0.027 * * *$ & $-0.031^{* * *}$ & $-0.027 * * *$ & $-0.031 * * *$ & $-0.027 * * *$ \\
\hline & & $(-2.61)$ & $(-4.44)$ & $(-3.01)$ & $(-3.96)$ & $(-3.37)$ & & $(-2.61)$ & $(-4.04)$ & $(-3.07)$ & $(-3.66)$ & $(-3.19)$ & & $(-2.69)$ & $(-3.38)$ & $(-2.78)$ & $(-3.15)$ & $(-2.74)$ \\
\hline Target ROA & & & -0.046 & -0.017 & -0.052 & -0.017 & & & -0.024 & 0.006 & -0.032 & 0.003 & & & -0.011 & 0.006 & -0.02 & 0.001 \\
\hline & & & $(-0.27)$ & $(-0.12)$ & $(-0.36)$ & $(-0.13)$ & & & $(-0.17)$ & $(0.05)$ & $(-0.26)$ & $(0.03)$ & & & $(-0.07)$ & $(0.05)$ & $(-0.15)$ & $(0.01)$ \\
\hline Percent Cash & & & $-0.001 * * *$ & $-0.001 *$ & $-0.001+$ & $-0.001+$ & & & $-0.001 *$ & $-0.001+$ & $-0.001+$ & $-0.001+$ & & & $-0.001+$ & $-0.001^{*}$ & -0.001 & -0.001 \\
\hline & & & $(-2.90)$ & $(-2.05)$ & $(-1.76)$ & $(-1.76)$ & & & $(-2.25)$ & $(-1.75)$ & $(-1.91)$ & $(-1.86)$ & & & $(-1,76)$ & $(-1.97)$ & $(-1.36)$ & $(-1.49)$ \\
\hline Industry FEs & No & No & No & Yes & No & Yes & No & No & No & Yes & No & Yes & No & No & No & Yes & No & Yes \\
\hline Quarterly FEs & No & No & No & No & Yes & Yes & No & No & No & No & Yes & Yes & No & No & No & No & Yes & Yes \\
\hline & 0.052 & 0.057 & 0.048 & 0.057 & 0.059 & 0.067 & 0.053 & 0.06 & 0.05 & 0.06 & 0.06 & 0.0 & $\overline{0.0}$ & 0.061 & 0.055 & 0.0 & 0.065 & 0.074 \\
\hline & 3,037 & 2,976 & 1,858 & 1,858 & 1,858 & 1,858 & 3,036 & 2,976 & 1,860 & 1,860 & 1,860 & 1,860 & 3,031 & 2,971 & 1,851 & 1,851 & 1,851 & 1,851 \\
\hline
\end{tabular}

(a) Panel A: Treatment = All US Targets (Jul. 2014 - Jun. 2017)

\begin{tabular}{|c|c|c|c|c|c|c|c|c|c|c|c|c|c|c|c|c|c|c|}
\hline \multirow[b]{3}{*}{ Treatme } & \multicolumn{6}{|c|}{ One Day Announcement Returns } & \multicolumn{6}{|c|}{ One Week Announcement Returns } & \multicolumn{6}{|c|}{ Four Week Announcement Returns } \\
\hline & [1] & [2] & {$[3]$} & [4] & [5] & [6] & [1] & [2] & [3] & [4] & {$[5]$} & [6] & [1] & {$[2]$} & [3] & [4] & {$[5]$} & [6] \\
\hline & $0.237 * * *$ & $\begin{array}{c}0.232 * * * \\
(10,03)\end{array}$ & $\frac{1.174^{* * *}}{(4.57)}$ & $\begin{array}{c}0.164^{* * *} \\
(4.92)\end{array}$ & $\begin{array}{c}0.165^{* * *} \\
(4.39)\end{array}$ & $\begin{array}{c}0.158^{* * *} \\
(4.49)\end{array}$ & $\begin{array}{c}0.242^{* * *} \\
(12.99)\end{array}$ & $\begin{array}{c}0.238 * * * \\
(9.17)\end{array}$ & $\begin{array}{c}0.179 * * * \\
(4.46\end{array}$ & $\begin{array}{c}0.168^{* * * *} \\
(4.72)\end{array}$ & $\begin{array}{c}0.169^{* * *} \\
(4.31\end{array}$ & $\begin{array}{c}0.161^{* * *} \\
(4.48)\end{array}$ & $\begin{array}{c}0.229 * * * \\
(13.64)\end{array}$ & $\begin{array}{c}0.228 * * * * \\
(9.71)\end{array}$ & $\begin{array}{c}0.188^{* * *} \\
(4.89)\end{array}$ & $\begin{array}{c}0.178^{* * *} \\
(4.75)\end{array}$ & $\begin{array}{c}0.178^{* * * *} \\
4.90\end{array}$ & $\frac{171 * * *}{0.17)^{1 * 5}}$ \\
\hline PostTrulia & $\begin{array}{c}0.137^{* * * *} \\
(7.49)\end{array}$ & $\begin{array}{c}0.142^{* * * *} \\
(8.00)\end{array}$ & $\begin{array}{c}0.114^{* * * *} \\
(3.29)\end{array}$ & $\begin{array}{c}0.115^{* * * *} \\
(3.05)\end{array}$ & & & $\begin{array}{c}0.140^{* * * *} \\
(6.87)\end{array}$ & $\begin{array}{c}0.144 * * * \\
(7.11)\end{array}$ & $\begin{array}{c}0.118^{* * * * *} \\
(3.54)\end{array}$ & $\begin{array}{c}0.119 * * * * \\
(3.16)\end{array}$ & & & $\begin{array}{c}0.140^{* * * *} \\
(.22)\end{array}$ & $\begin{array}{c}0.145^{* * * *} \\
(8.03)\end{array}$ & $\begin{array}{c}0.129 * * * * \\
(4.56)\end{array}$ & $0.131^{* * * *}$ & & \\
\hline reatment x PostTrulia & $-0.133 * * *$ & $-0.132 * * *$ & $-0.086^{*}$ & -0.078 & -0.072 & -0.066 & $-0.134 * * *$ & $-0.134 * * *$ & $-0.090 * *$ & $-0.081+$ & -0.074 & -0.068 & $-0.123 * * *$ & $-0.125 * * *$ & $-0.093 * * *$ & $-0.084^{*}$ & $-0.080+$ & -0.074 \\
\hline & $(-3.83)$ & $(-5.40)$ & $(-2.02)$ & $(-1.56)$ & $(-1.34)$ & $(-1.18)$ & $(-3.83)$ & $(-5.31)$ & $(-2.39)$ & $(-1.77)$ & $(-1.51)$ & $(-1.28)$ & $(-3.32)$ & $(-4.61)$ & $(-3.16)$ & $(-2.10)$ & $(-1.79)$ & $(-1.47)$ \\
\hline Ln(Target Assets) & & $-0.016^{*}$ & $-0.023^{* * *}$ & $-0.019 * * *$ & $-0.024^{* *}$ & $-0.021^{* *}$ & & $-0.018+$ & $-0.024 * * *$ & $-0.020^{*}$ & $-0.025^{* * *}$ & $-0.022 * *$ & & $-0.021^{*}$ & $-0.025 * *$ & $-0.021+$ & $-0.026^{* *}$ & $-0.023+$ \\
\hline Target ROA & & & $\begin{array}{l}(-3.38) \\
-0.026\end{array}$ & $\begin{array}{c}(-2.62) \\
0.001\end{array}$ & $\begin{array}{r}(-2.55) \\
-0.042\end{array}$ & $\begin{array}{l}(-2.49) \\
-0.006\end{array}$ & & & $\begin{array}{c}(-3.03) \\
0.018\end{array}$ & $\begin{array}{l}(-2.13) \\
0.055\end{array}$ & $\begin{array}{l}(-2.59) \\
-0.002\end{array}$ & $\begin{array}{c}(-2.44) \\
0.041\end{array}$ & & & $\begin{array}{c}(-2.56) \\
0.029\end{array}$ & $\begin{array}{l}(-1.81) \\
0.051\end{array}$ & $\begin{array}{r}(-2.46) \\
0.007\end{array}$ & $\begin{array}{r}(-1.94) \\
0.036\end{array}$ \\
\hline & & & $(-0.15)$ & $(0.00)$ & $(-0.30)$ & $(-0.05)$ & & & $(0.12)$ & $(0.42)$ & $(-0.02)$ & (0.37) & & & (0.18) & (0.37) & $(0.06)$ & $(0.31)$ \\
\hline Percent Cash & & & $-0.001^{* *}$ & $-0.001 *$ & -0.001 & -0.001 & & & $-0.001^{*}$ & -0.001 & -0.001 & -0.001 & & & -0.001 & -0.001 & -0.001 & -0.001 \\
\hline & & & $(-2.43)$ & $(-2.04)$ & $(-1.44)$ & $(-1.54)$ & & & $(-2.06)$ & $(-1.45)$ & $(-1.22)$ & $(-1.39)$ & & & $(-1.62)$ & $(-1.29)$ & $(-1.41)$ & $(-1.20)$ \\
\hline Industry FEs & No & No & No & Yes & No & Yes & No & No & No & Yes & No & Yes & No & No & No & Yes & No & Yes \\
\hline Quarterly FEs & No & No & No & No & Yes & Yes & No & No & No & No & Yes & Yes & No & No & No & No & Yes & Yes \\
\hline & 0.047 & 0.05 & 0.047 & 0.059 & 0.061 & 0.072 & 0.048 & 0.052 & 0.05 & 0.062 & 0,063 & 0.076 & 0.044 & 0.052 & 0.052 & 0.064 & 0.066 & 0.077 \\
\hline & 2,684 & 2,632 & 1,596 & 1,596 & 1,596 & 1,596 & 2,679 & 2,628 & 1,596 & 1,596 & 1,596 & 1,596 & 2,676 & 2,624 & 1,588 & 1,588 & 1,588 & 1,588 \\
\hline
\end{tabular}

(b) Panel B: Treatment = Only Delaware Targets (Jul. 2014 - Jun. 2017)

Note: Each panel presents OLS estimations with industry- and year-clustered standard errors on several dependent variables corresponding to natural log of the 1-day, 1-week and 4-week gross stock price premium on announcement date, for public target acquisitions in excess of $\$ 100 \mathrm{~m}$ deal value where at least $50 \%$ of voting shares are sought. The January 2016 Trulia decision in the Delaware Chancery Court is the common treatment event, and the coefficient on the cross-product Treatment x PostTrulia is the diff-in-diff estimate. Foreign targets constitute the control group. Panel A reports estimates where all US targets are part of the treatment group, while Panel B drops non- Delaware US targets from the data set. Estimated t-statistics are in parentheses. Notation: $\left\{+,{ }^{*}, * *, * * *\right\}$ denote significance at the $p=\{0.10,0.05,0.02,0.01\}$ levels $(2$-sided test). Data Source: Thompson Reuters SDC Platinum Database (Jul. 2014 - Jun. 2017).

Table 7: Difference-in-Difference results (balanced panel)

are worth noting: If the proponents of Trulia were correct that disclosure settlements represented an wasteful and inefficient "deal tax" on negotiated acquisitions, one would expect average premia to increase (possibly substantially) across treated firms. The fact that our estimated effect is uniformly negative (though only mildly so) raises a legitimate question about whether shareholders of target companies were truly helped by the Trulia outcome. Viewed in the context of our theoretical model, these results constitute evidence that 
the reforms introduced by Trulia were of questionable economic value from the standpoint of shareholder welfare.

\section{Conclusion}

Life is complicated. And so, evidently, is law. In this paper, we have used the landmark Trulia decision to demonstrate both of these claims in the context of the rise (and recent fall) of "disclosure-only" settlements of MOLs. The decision was celebrated by many as a needed elixir for perceived "shake down" lawsuits brought by attorneys with interests that were skewed away from the shareholders they represented. Our analysis - while accepting this general diagnosis - also demonstrates the challenge of designing responsive regulatory responses. Using a plausible theoretical model of shareholder litigation and settlement, we have demonstrated there is no a priori reason to expect managerial agency costs remain constant while one attempts to "fix" attorney-born agency costs. A seemingly sensible solution as to the latter (e.g., the Trulia doctrine) can unwittingly introduce hidden costs on the former. Consequently, on a purely conceptual level, we have demonstrated that law and policy makers must take care to anticipate the equilibrium effects of their policy changes across all dimensions. Second, our theoretical analysis delivers predictions that are empirically testable. Our empirical efforts yield little evidence that Trulia represented an unalloyed gain to target shareholders. To the contrary, the treatment event appears to have had either no effect on merger premia or (perhaps) even a slight deflationary one - a sufficient equilibrium condition for shareholder welfare loss in our model. Although the reforms visited by Trulia my yet prove beneficial, based on available data we are unable to conclude that such a promise has yet to be realized (at least from target shareholders' perspective).

There are several extensions of our analysis that are worthy of attention, but time and space constraints do not allow us to explore them here. Theoretically, the model developed above might be extended to allow different allocations of bargaining power and information. For instance, we might extend the analysis to allow the defendant to enjoy some bargaining power against the plaintiff attorney, or the buyer to gain bargaining power against the target manager. Relatedly, the model might be enriched to permit private information as to the content of the buyer's valuation $(v)$, the attorney's cost of case development $(k)$, or the parties' respective costs of litigation $(c)$. We conjecture that many of these permutations - while no doubt interesting - would ultimately serve to underscore a central meta-theme of this paper: That the policy landscape is complicated, and that Trulia's effort to ameliorate one agency cost (attorney-shareholder) may still plausibly exacerbate others (e.g., manager-shareholder). Note, moreover, that the model presented here already yields several predictions that closely track key features of the MOL debate, including (a) the important agency costs on multiple levels; (b) the equilibrium occurrence of abandonment (early and late), settlement (early and late) and litigation, even within a complete information model; and (c) the emergence of firms that "specialize" in extracting disclosure settlements. We therefore defer such extensions to a later date.

Empirically, the analysis might attempt to harness more effectively other equilibrium predictions of the model. For example, Proposition 3 predicts that an upward shock to $\tau$ should also decrease deal frequency, holding constant predictors of acquisitions. With sufficient firm-level data, it might be possible to estimate propensity scores for becoming a target, both before and after Trulia, testing the hypothesis that the opinion induced a negative shock in the underlying hazard rate for treated firms. This extension would likely require significantly more data, however, including firm-level operating and returns data that are difficult to obtain for foreign targets. Nevertheless, conditional on data availability, such an extension seems eminently worth pursuing. 
Finally, we reiterate a caveat stated in the introduction of this paper: Although our assessment of the Trulia doctrine leans toward the negative (or at least skepticism about the positive case), we do not counsel policy makers or courts to abandon engaging in experimentation. While life and law are complicated, experimentation is critical for learning their contours. That learning curve, moreover, is simply unattainable without taking the first step. The Trulia doctrine, no doubt, will evolve and change as we continue to generate additional information about the incidence and costs associated with the myriad agency costs that imbue mergers and acquisitions practice. We hope this analysis may be of use in planning and executing ensuing steps.

\section{References}

Cain, Matthew D. and Steven Davidoff Solomon. 2015. "A Great Game: The Dynamics of State Competition and Litigation." Iowa Law Review 100 (2):465-500.

Cain, Matthew D and Steven Davidoff Solomon. 2016. "Takeover Litigation in 2015." URL http://ssrn. com/abstract=2715890.

CornerstoneResearch. 2018. "Shareholder Litigation Involving Acquisitions of Public Companies: Review of 2017 Litigation." .

Daughety, Andrew F. and Jennifer F. Reinganum. 2012. "Settlement."

Fisch, Jill E., Sean J. Griffith, and Steven Davidoff Solomon. 2015. "Confronting the Peppercorn Settlement in Merger Litigation: An Empirical Analysis and a Proposal for Reform." Texas Law Review 93 (3):557-624.

Friedlander, Joel Edan. 2016. "How Rural/Metro Exposed the Systemic Problem of Disclosure Settlements." Delaware Journal of Corporate Law 40 (3):877-919. URL http://dx.doi.org/10.2139/ssrn.2689877.

Griffith, Sean J. 2015. "Correcting Corporate Benefit : How To Fix Shareholder Litigation By Shifting the Doctrine on Fees." Boston College Law Review 56 (1):1-60.

Issacharoff, Samuel. 2014. "Litigation Funding and the Problem of Agency Cost in Representative Actions." DePaul Law Review 63 (2):561-585.

Markel, Greg and Gillian Burns. 2015. "Assessing A Judicial Solution To Abusive Merger Litigation." Law 360 .

Spitzer, Matthew and Eric Talley. 2014. "On Experimentation and Real Options in Financial Regulation." Journal of Legal Studies 43 (3):S121-S149.

Talley, Eric L. and Albert H. Choi. 2016. "Appraising the 'Merger Price' Appraisal Rule."

\section{List of cases}

Amer. Mining Corp. v. Theriault, 51 A.3d 1213 (Del. 2012) Am. Mining Corp. v. Theriault, 51 A.3d 1213, 1254 (Del. 2012).

In Re Aruba Networks SH Litigation CA\# 10765 (Vice Chancellor Laster) (Oct. 9. 2015).

Corwin v. KKR Financial Holdings LLC, 125 A.3d 304 (Del. 2015) 
In re Orchard Enterprises Shareholder Litigation (C.A. No. 7840-VCL) (2014).

In re PAETEC Holding Corp. S'holders Litig., C.A. No. 6761-VGC (Del. Ch. Mar. 19, 2013).

In re Riverbed Tech., 2015 WL 5458041 (Vice Chancellor Glasscock) (September 17, 2015).

In re Trulia, Inc. Stockholder Litigation, C.A. No. 10020-CB (Chancellor Bouchard) (January 22, 2016).

In re Saba Software, Inc. Stockholder Litigation (C.A. No. 10697-VCS) (Del. Ch,. 2017)

In re. Sauer-Danfoss Inc. S?holders Litig., 2011 WL 2519210 (Del. Ch. Apr. 2011).

Kazman v. Frontier Oil Corp. 398 S.W.3d 377 (14th Dist. 2013).

Retirement System v. Black, C.A. 9410-VCN (Del. Ch. Feb. 19, 2016).

Rocker v. Centex Corp., 377 S.W.3d 907 (Tex. App. 2012).

Sugarland Industries, Inc. v. Thomas, 420 A.2d 142 (Del. 1980).

Transatlantic Holdings Inc. Shareholders Litigation, Case No. 6574-CS (2013). 


\section{Appendix}

\section{A Theory}

\section{A.1 Shareholder approval}

Given the timing and structure of the game and the fact that voting costs are zero in the model, it is clear that if $p \geq \hat{p}$, then each shareholder will weakly prefer to vote in favor of the merger proposal; ${ }^{61}$ should early or late settlement follow, shareholders would earn $p+\tau t>\hat{p}$ or $p+\sigma s>\hat{p}$, respectively, which would only reinforce their support for the merger. Vice versa, shareholders will reject any proposal than earns them less than $\hat{p}$ in total. However, this does not necessarily imply that the initial price should be $p \geq \hat{p}$, since, in theory, the manager could demand from the buyer a lower price, $p<\hat{p}$ - coupled with a conveniently higher $b$ - and then count on settlement $t$ or $s$ to make up the difference between $p$ and $\hat{p}$. However, offering $p<\hat{p}$ is never in the manager's interest, because deal prices below $\hat{p}$ make the merger conditional on the occurrence of settlement and hence give the plaintiff attorney an ex post veto power: unless the buyer settles there will be no merger. Since a portion of the settlement amount pays for the plaintiff attorney's fee and is not pocketed by the shareholders, it is more costly to top up the price of the merger through subsequent settlements rather than to increase the deal price directly upfront. Lemma (1) formalizes this intuition.

Lemma 1. The buyer's expected payoff from the acquisition, including litigation exposure, is negative for any value of $b$ when $p<\hat{p}$.

Proof. Table (8) recoups the buyer's payoff in the standard setting, with assured shareholder approval. The table is obtained by subtracting the buyer's litigation costs reported in Table (11) from the net value of the merger $(v-p-b)$.

\begin{tabular}{|c|c|c|c|}
\hline & $p^{*} \leq p$ & $p<p^{*} \leq \bar{p}$ & $p^{*}>\bar{p}$ \\
\hline$k \geq \bar{k}$ & \multicolumn{3}{|c|}{$v-p-b$} \\
\hline$\underline{k} \leq k<\bar{k}$ & \multicolumn{3}{|c|}{$v-p-b-t$} \\
\hline$k<\underline{k}$ & $v-p-b$ & $v-p-b-s$ & $-2 c-(1-\sigma)\left(p^{*}-p\right)$ \\
\hline
\end{tabular}

Table 8: Buyer's payoff with $p \geq \hat{p}$

Let us now rewrite these payoffs in Table (9) for the case with $p<\hat{p}$. We focus on the case in which the manager's TIOLI merger offer to the buyer is such that $v-p-b \geq 0$, if this is not the case the buyer would not want to enter into a merger agreement to start with. Let us start from the right in the last

\begin{tabular}{c||c|c|c|}
\multicolumn{1}{c||}{} & $p^{*} \leq p$ & \multicolumn{1}{c|}{$p<p^{*} \leq \bar{p}$} & $p^{*}>\bar{p}$ \\
\hline \hline$k \geq \bar{k}$ & \multicolumn{3}{|c|}{0} \\
\cline { 2 - 4 }$\underline{k} \leq \leq k \bar{k}$ & \multicolumn{3}{|c|}{$-\int_{p}^{\infty}\left(2 c+(1-\sigma)\left(p^{*}-p\right)\right) d F_{p^{*}}\left(p^{*}\right)$} \\
\cline { 2 - 4 }$k<\underline{k}$ & 0 & $-2 c-(1-\sigma)\left(p^{*}-p\right)$ & $-2 c-(1-\sigma)\left(p^{*}-p\right)$ \\
\cline { 2 - 4 } & &
\end{tabular}

Table 9: Buyer's payoff with $p<\hat{p}$

row of Table (9). The injunction payoff remains the same and is negative. Moving left, the late settlement outcome is also negative because it tracks the injunction outcome. Note that this is irrespective of whether

\footnotetext{
${ }^{61}$ We ignore here the multiplicity of equilibria arising when considering the voting behavior of shareholders in the aggregate when the voting rule is majoritarian. See Talley and Choi (2016) showing that the elimination of weakly dominated alternatives removes such multiplicity.
} 
shareholders approve the merger or not. If $p+\sigma s \geq \hat{p}$ then shareholders approve the merger and we are in the standard setting; the buyer's payoff is $v-p-b-s=-2 c-(1-\sigma)\left(p^{*}-p\right)<0$. If $p+\sigma s<\hat{p}$ then the shareholders do not approve the merger upon a late settlement and hence the settlement amount is $s^{i}=2 c+(1-\sigma)\left(p^{*}-p\right)$ - that is, $s^{i}$ leaves out the net value of the merger because the merger does not go through - and the buyer's payoff is equal to $-s^{i}=-2 c-(1-\sigma)\left(p^{*}-p\right)$ as before. This shows that the late settlement payoff is invariant to shareholder approval - the value of which would be fully captured by the plaintiff attorney - and that it is not advantageous for the buyer to increase $s^{i}$ in order to bring the total payoff of the shareholders at $\hat{p}$ and secure a positive vote.

Let us now move to the left-most box in the last row: the late abandonment scenario. In this case. the buyer invariably earns 0. As a default, shareholders would reject the merger and hence the buyer earns nothing; if the attorney came to the rescue and offered a settlement whose only purpose was to top up the price, she would be able to extract the entire buyer's surplus from the merger by setting her TIOLI settlement offer at $v-p-b$, resulting again in a payoff equal to zero. Which of these two outcomes occurs depends on the magnitude of $\sigma$ and on whether the buyer's surplus is large enough to satisfy the shareholders given that a fraction $1-\sigma$ of it will be pocketed by the attorney. If $\sigma(v-p-b) \geq \hat{p}-p$ settlement is possible- this is the case when $p$ is relatively large and $b$ relatively small-while if $\sigma(v-p-b)<\hat{p}-p$, the tax imposed by the attorney will make settlement impossible. We can conclude that, for any probability of occurrence of each of the three possible outcomes at the late settlement and litigation stage, the expected payoff for the buyer is (weakly) negative.

We can now examine the early settlement stage in the middle row of Table (9). As before, we have to consider two scenarios. If $p+\tau t \geq \hat{p}$, then shareholders will approve the merger following an early settlement. Since proceeding to the later stage yields a negative payoff, the attorney can extract the full value of the merger plus the costs to be saved at the later stage and hence the buyer will face a negative expected payoff at the early stage, that is,

$$
t^{i}=v-p-b+\int_{p}^{\infty}\left(2 c+(1-\sigma)\left(p^{*}-p\right)\right) d F_{p^{*}}\left(p^{*}\right)
$$

and

$$
v-p-b-t^{i}=-\int_{p}^{\infty}\left(2 c+(1-\sigma)\left(p^{*}-p\right)\right) d F_{p^{*}}\left(p^{*}\right)<0
$$

If instead, $p+\tau t<\hat{p}$, then the early settlement amount is not enough to appease the shareholders and there will be no merger following an early settlement. Yet, the attorney can extract a positive settlement, which will save the buyer the costs of going forward and hence the buyer's expected payoff at the early settlement stage is equal to

$$
-t^{i i}=-\int_{p}^{\infty}\left(2 c+(1-\sigma)\left(p^{*}-p\right)\right) d F_{p^{*}}\left(p^{*}\right)<0
$$

Finally, the first row in Table (9) refers to the early abandonment case of no filing. Here the buyer needs the attorney to top up the price with a settlement offer, which the attorney may make, extracting the full value of the merger, if that covers her filing costs. Since all outcomes yield a (weakly) negative payoff, we can conclude that setting $p<\hat{p}$ leads to a negative expected payoff for the buyer, for any level of $b$ and irrespective of the probability of occurrence of each of the outcomes in Table (9). This indicates that, for any given $b$, the buyer's expected payoff can be increased by raising the deal price from $p<\hat{p}$ to $\hat{p}$. This in turn is beneficial for the manager because it guarantees the buyer's participation without reducing the private gain 
$b$.

\section{A.2 Filing thresholds}

Table 2 shows that the payoff from filing is negative for high types, that is, if $k \geq \alpha$. However, even if $k<\alpha$, the attorney finds it advantageous to file a suit only if the filing costs are less than her expected returns from filing. Therefore, some intermediate types (that is, attorneys who would settle early after filing) and possibly even low types (attorneys who would refuse to settle early and proceed to the next stage after filing) could decide not to file a case. We define in Lemma 2 a filing threshold $\bar{k}$ that can take three different values depending on the magnitude of the portion $\phi$ of attorney's effort that has to be devoted to case preparation and filing and of the fraction $\tau$ of the early settlement amount that has to be paid out to the shareholders. (Recall that $\alpha$ and $t$ are not functions of $\phi$ and $\tau$.)

$$
\bar{k}=\left\{\begin{array}{llll}
\bar{k}_{3} \equiv \frac{\alpha}{1+\phi} & \text { if } \quad \tau>1-\frac{\phi}{1+\phi} \frac{\alpha}{t} & \text { case } 3 \\
\bar{k}_{2} \equiv \frac{1-\tau) t}{\phi} & \text { if } \quad 1-\phi \frac{\alpha}{t} \leq \tau<1-\frac{\phi}{1+\phi} \frac{\alpha}{t} & \text { case } 2 \\
\bar{k}_{1} \equiv \alpha & \text { if } \quad \tau<1-\phi \frac{\alpha}{t} & \text { case } 1
\end{array}\right.
$$

If $\tau$ and $\phi$ are relatively low-that is, when $\tau<1-\phi \frac{\alpha}{t}$, case 1 - then the filing threshold is $\bar{k}=\alpha$. With low filing costs and expecting a large portion of the early settlement, all the intermediate and low type attorneys file a case, as in Table 10a. If $\tau$ and $\phi$ take intermediate values - that is, if $1-\phi \frac{\alpha}{t} \leq \tau<1-\frac{\phi}{1+\phi} \frac{\alpha}{t}$, case 2 - then $\bar{k}=\frac{(1-\tau) t}{\phi}$. In this case, some of the intermediate types would have a credible threat to go to trial $(k<\alpha)$ but do not file because the settlement amount they would earn is less than the filing costs $\left(k \geq \frac{(1-\tau) t}{\phi}\right)$. The remaining intermediate types and all the low types file, again as in Table 10a. Finally, if $\tau$ and $\phi$ take large values - that is, if $\tau \geq 1-\frac{\phi}{1+\phi} \frac{\alpha}{t}$, case 3 - attorneys face large filing costs that have to be balanced against meager early settlement amounts or relatively low expected returns from proceeding to the later stages of litigation. In this case, $\bar{k}=\frac{\alpha}{1+\phi} \leq \underline{k}$ : The filing threshold is lower than the early litigation threshold. Now only some low types file as in Table 10b and there is no filed case that results in an early settlement, due to the fact that all intermediate types abandon early.

\begin{tabular}{c||c|c|c|}
\multicolumn{1}{|||||}{} & $p^{*} \leq p$ & $p<p^{*} \leq \bar{p}$ & $p^{*}>\bar{p}$ \\
\hline \hline$k \geq \bar{k}$ & \multicolumn{3}{|c|}{ No filing } \\
\hline$\underline{k} \leq k<\bar{k}$ & \multicolumn{3}{|c|}{ Early settlement } \\
\hline \multicolumn{1}{c||}{$k<\underline{k}$} & Late abandonment & Late settlement & Injunction \\
\cline { 3 - 4 } & &
\end{tabular}

(a) Cases (1) and (2) $(\underline{k}<\bar{k})$

\begin{tabular}{c||c|c|c|}
\multicolumn{1}{l||}{} & $p^{*} \leq p$ & $p<p^{*} \leq \bar{p}$ & $p^{*}>\bar{p}$ \\
\hline \hline$k \geq \bar{k}$ & \multicolumn{3}{|c|}{ No filing } \\
\hline$k<\bar{k}$ & Late abandonment & Late settlement & Injunction \\
\cline { 2 - 4 } & &
\end{tabular}

(b) Case $3(\underline{k} \geq \bar{k})$

Table 10: Litigation and settlement outcomes

Lemma 2. Let $\bar{k}$ be the filing threshold. We have three cases:

$$
\text { If } \tau<1-\phi \frac{\alpha}{t} \text {, then } \bar{k}=\alpha \text { and all the intermediate and low types file as in Table 10a. }
$$

If $1-\phi \frac{\alpha}{t} \leq \tau<1-\frac{\phi}{1+\phi} \frac{\alpha}{t}$, then $\bar{k}=\frac{(1-\tau) t}{\phi}$ and some of the intermediate types and all low types file, again as in Table 10a. 


$$
\text { If } \tau \geq 1-\frac{\phi}{1+\phi} \frac{\alpha}{t} \text {, then } \bar{k}=\frac{\alpha}{1+\phi} \text { and only some low types file as in Table } 10 b \text {. }
$$

Proof. Low-type attorneys who, conditional on filing, would abandon-that is, those with $k \geq \alpha$ - do not file because the payoff from filing is negative. Intermediate-type attorneys who, conditional on filing, would settle early - that is, those with $\underline{k} \leq k<\alpha$-file a case if the filing and preparation costs are less than the expected early settlement amount, that is, if $k<\frac{(1-\tau) t}{\phi}$. Hence the attorney's type $k$ must be smaller than both $\alpha$ and $\frac{(1-\tau) t}{\phi}$ for the attorney to file and have a credible threat to proceed (which is necessary to extract a positive settlement amount $t$ ). Finally, low-types attorneys who, conditional on filing, refuse to settle early and proceed to the next litigation stage - that is, those with $k<\underline{k}$, file if their expected payoff is positive, that is, if $k<\frac{\alpha}{1+\phi}$. Let us therefore define the following filing threshold

$$
\bar{k} \equiv \max \left\{\min \left\{\alpha, \frac{(1-\tau) t}{\phi}\right\}, \frac{\alpha}{1+\phi}\right\}
$$

such that an attorney files if $k<\bar{k}$ and does not file otherwise. The element $\alpha$ in the set above guarantees that filing attorneys have a credible threat to proceed to the next stage and hence either proceed or are able to extract a settlement amount. The element $\frac{(1-\tau) t}{\phi}$ in the set guarantees that the filing intermediate types receive a positive payoff. For an intermediate type to file, $k$ must be less that both these thresholds. Finally, the last element in the set, $\frac{\alpha}{1+\phi}$, is a threshold that is activated when not even the marginal intermediate type (the attorney who is indifferent between settling early and proceeding) receives a positive payoff. We can distinguish among three cases.

1. If $\tau<1-\phi \frac{\alpha}{t}$, then we have $\frac{\alpha}{1+\phi}<\alpha<\frac{(1-\tau) t}{\phi}$; hence $\bar{k}=\alpha$. The attorney's payoff decreases in $k$ (see Table 2). Hence, since $(1-\tau) t-\phi k>(1-\tau) t-\phi \alpha>0$ if $\underline{k} \leq k<\alpha$, then all intermediate types receive a positive payoff from filing and hence file a case. Moreover, $\underline{k}<\bar{k}$ and hence all the low types also file a lawsuit (their payoff is never less than that of intermediate types).

2. If $1-\phi \frac{\alpha}{t} \leq \tau<1-\frac{\phi}{1+\phi} \frac{\alpha}{t}$, then we have $\frac{\alpha}{1+\phi}<\frac{(1-\tau) t}{\phi}<\alpha$; hence $\bar{k}=\frac{(1-\tau) t}{\phi}$ and some of the intermediate types do not file a case. Namely, intermediate-type attorneys with $\frac{(1-\tau) t}{\phi} \leq k<\alpha$ would have a credible threat to go to trial and hence be able to extract a positive early settlement, but the amount of the settlement is less than the filing costs. In this case, we still have $\underline{k}<\bar{k}$ and hence all the low types file a lawsuit.

3. If $\tau \geq 1-\frac{\phi}{1+\phi} \frac{\alpha}{t}$, then we have $\frac{(1-\tau) t}{\phi}<\frac{\alpha}{1+\phi}<\alpha$; hence $\bar{k}=\frac{\alpha}{1+\phi}<\underline{k}$. This implies that all intermediate-type attorneys receive a negative payoff from filing and hence do not file. To see why, consider that the intermediate type with the largest payoff is the type $k=\underline{k}$. Replacing $\underline{k}$, her payoff is $(1-\tau) t-\phi \underline{k}=(1+\phi)(1-\tau) t-\phi \alpha<0$. Moreover, some low-type attorneys (those with $\frac{\alpha}{1+\phi} \leq k<\underline{k}$ ) receive a negative payoff, $\alpha-(1+\phi) k<0$ (see Table 2 ), and hence do not file. Thus, only some lowtype attorneys file a suit in this case and all filed cases proceed to later litigation stages. There is no early settlement in this case.

\section{A.3 Buyer's expected litigation exposure}

Following Table 3, we can identify the litigation costs in each future contingency as indicated in Table 11. Note that the injunction does not only generate out-of-pocket costs for the buyer-which are equal to the attorney's fee $(1-\sigma)\left(p^{*}-p\right)$ - but it also results in an opportunity cost (the failed merger) equal to $v-p-b$. 
Since, $s=v-p-b+2 c+(1-\sigma)\left(p^{*}-p\right)$, the cost of settling late is equal to the cost of the injunction for the buyer and hence $t=\int_{p}^{\infty} s d F_{p^{*}}\left(p^{*}\right)$; we have:

$$
\begin{aligned}
\lambda & = \begin{cases}\int_{0}^{\bar{k}} \int_{p}^{\infty} s d F_{p^{*}}\left(p^{*}\right) d F_{k}(k) & \text { if } \tau \geq 1-\frac{\phi}{1+\phi} \frac{\alpha}{t} \\
\int_{0}^{\underline{k}} \int_{p}^{\infty} s d F_{p^{*}}\left(p^{*}\right) d F_{k}(k)+\int_{\underline{k}}^{\bar{k}} \int_{-\infty}^{\infty} t d F_{p^{*}}\left(p^{*}\right) d F_{k}(k) & \text { if } 1-\frac{\alpha}{t} \leq \tau<1-\frac{\phi}{1+\phi} \frac{\alpha}{t} \\
\int_{0}^{\bar{k}} \int_{-\infty}^{\infty} t d F_{p^{*}}\left(p^{*}\right) d F_{k}(k) & \text { if } \tau<1-\frac{\alpha}{t}\end{cases} \\
& =t F_{k}(\bar{k})
\end{aligned}
$$

where, ${ }^{62}$ in cases 1 and 2 , the first addendum is the buyer's cost from late settlement or injunction, and the second addendum is the cost from early settlement; in case 3 there is no early settlement. Given that the buyer/defendant has no bargaining power at settlement negotiations with the attorney, the early settlement amount $t$ reflects perfectly her costs of going forward with the litigation. This makes the ex ante cost of the different litigation outcomes equal to $t$. Therefore, the buyer's exposure to litigation is simply equal to the early settlement amount $t$ times the probability to be matched with an attorney who will file a lawsuit.

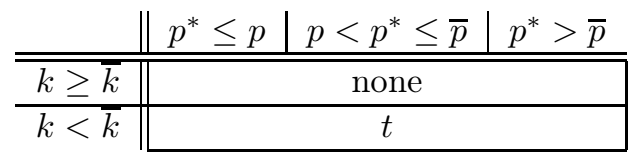

(a) Low Trulia parameter $\left(\tau<1-\frac{\alpha}{t}\right)$

\begin{tabular}{c||c|c|c|}
\multicolumn{1}{l||}{} & $p^{*} \leq p$ & $p<p^{*} \leq \bar{p}$ & $p^{*}>\bar{p}$ \\
\hline \hline$k \geq \bar{k}$ & \multicolumn{3}{|c|}{ none } \\
\hline$\underline{k} \leq k<\bar{k}$ & \multicolumn{3}{|c}{$t$} \\
\hline$k<\underline{k}$ & none & $s$ & $v-p-b+2 c+(1-\sigma)\left(p^{*}-p\right)$ \\
\cline { 2 - 4 } & & &
\end{tabular}

(b) Intermediate Trulia parameter $\left(1-\frac{\alpha}{t} \leq \tau<1-\frac{\phi}{1+\phi} \frac{\alpha}{t}\right)$

\begin{tabular}{c||c|c|c|} 
& $p^{*} \leq p$ & $p<p^{*} \leq \bar{p}$ & $p^{*}>\bar{p}$ \\
\hline \hline$k \geq \bar{k}$ & \multicolumn{3}{|c|}{ none } \\
\hline$k<\bar{k}$ & none & $s$ & $v-p-b+2 c+(1-\sigma)\left(p^{*}-p\right)$ \\
\cline { 2 - 3 }
\end{tabular}

(c) High Trulia parameter $\left(\tau \geq 1-\frac{\phi}{1+\phi} \frac{\alpha}{t}\right)$

Table 11: Buyer's litigation costs

\section{A.4 Proof of Proposition 1}

To prove Proposition 1 it is enough to identify parameter values and functional forms that yield the result. We focus on price increase and price decrease (that the price can remain constant follows from a continuity argument). To do so, we calculated the equilibrium price for levels of $\tau$ between 0 and 1 using 0.02 increases, that is, we run each simulation 50 times. The simulations were run using Wolfram Mathematica 11. Table 12 summarizes the parameter values of the functional forms. We used a triangular distribution for $p^{*}$, with a single peak at $p^{*}=v$ and slope parameter $\xi_{p^{*}}$; we used a linear, increasing distribution for $k$, with a slope parameter $\xi_{k}$. Simulation codes are available upon request. The figures 4 and 6 display the density and cumulative distribution functions used in the simulations. The two simulations differ only with respect to the distribution of $p^{*}$. In the distribution "price increase", the court assessment of the fair price is more tightly

\footnotetext{
${ }^{62}$ Note that $t$ is neither a function of $k$ (which is expended earlier in the game) nor of $p^{*}$ (because $p^{*}$ is the argument of integration while calculating $t)$ and hence $\int_{-\infty}^{\infty} t d F_{p^{*}}\left(p^{*}\right)=t$ and $\int_{-\infty}^{\bar{k}} t d F_{k}(k)=t d F_{k}(\bar{k})$.
} 


\begin{tabular}{|c|c|c|}
\hline & Simulation "price decrease" & Simulation "price increase" \\
\hline $\bar{v}$ & \multicolumn{2}{|c|}{100} \\
\hline$p^{*}(\min$ and $\max )$ & {$[1,19]$} & {$[5,15]$} \\
\hline$f_{p^{*}}\left(p^{*}\right)=\{$ & \multicolumn{2}{|c|}{$\begin{array}{cll}0 & \text { if } & p^{*}<p_{\min }^{*} \\
\frac{1}{2} \frac{\xi_{p^{*}}}{v-p_{\min }^{*}}+\left(p^{*}-p_{\min }^{*}\right) \frac{\xi_{p^{*}}}{\left(v-p_{\min }^{*}\right)^{2}} & \text { if } & p_{\min }^{*} \leq p^{*} \leq v \\
\frac{1}{2} \frac{1+\xi_{p^{*}}}{p_{\max }^{*}-v}-\left(p^{*}-v\right) \frac{\xi_{p^{*}}}{\left(p_{\max }^{*}-v\right)^{2}} & \text { if } & v<p^{*} \leq p_{\max }^{*} \\
0 & \text { if } & p^{*}>p_{\max }^{*}\end{array}$} \\
\hline$\overline{\xi_{p^{*}}}$ & \multicolumn{2}{|c|}{.5} \\
\hline$k(\min$ and $\max )$ & \multicolumn{2}{|c|}{$[0,3]$} \\
\hline$f_{k}(k)=\left\{\frac{1}{k_{\max }}\right.$ & $\begin{array}{c}0 \\
\frac{-\xi_{k}}{-k_{\min }}+\left(k-k_{\min }\right) \frac{2 \xi_{k}}{\left(k_{\max }-k_{\min }\right)^{2}} \\
0\end{array}$ & $\begin{array}{l}\text { if } \quad k<k_{\min } \\
\text { if } \quad k_{\min } \leq k \leq k_{\max } \\
\text { if } k>k_{\max }\end{array}$ \\
\hline$\overline{\xi_{k}}$ & \multicolumn{2}{|c|}{.75} \\
\hline$\sigma$ & \multicolumn{2}{|c|}{.75} \\
\hline$\phi$ & \multicolumn{2}{|l|}{.3} \\
\hline$c$ & \multicolumn{2}{|c|}{.01} \\
\hline$\psi$ & \multicolumn{2}{|l|}{0} \\
\hline
\end{tabular}

Table 12: Parameter values and functional forms

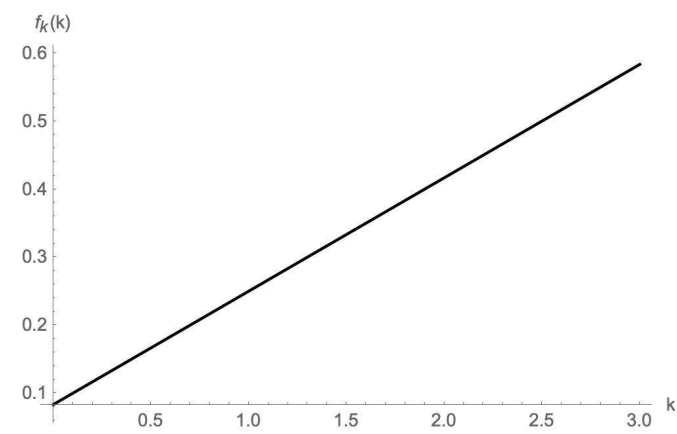

(a) Density function for $k$

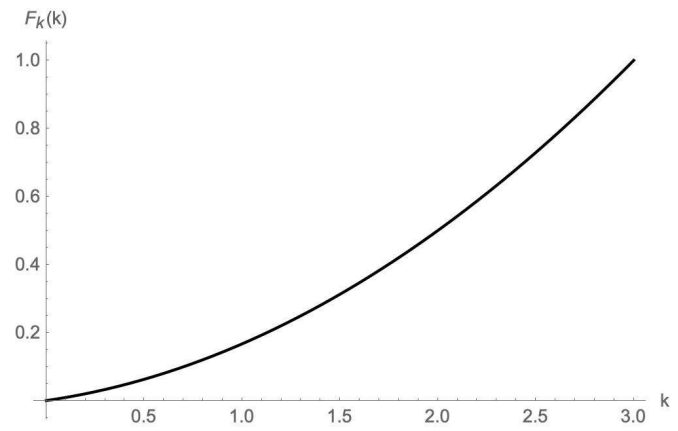

(b) Cumulative distribution function for $k$

Figure 6: Simulated distribution for $k$

distributed around the buyer's valuation $v$. When the court is better at assessing the value of the proposed merger there is less scope for late abandonment - which occurs only at the lower end of the distribution of $p^{*}$-and hence the sanction imposed by litigation on low-prices deals is greater. An increase in $\tau$ makes more of the filed case proceed to the later stages of litigation and hence magnifies this effect, pushing deal prices up. The opposite occurs in the simulation "price decrease".

\section{A.5 Proof of Proposition 2}

Proof. Using the Envelop Theorem and the fact that $\frac{\partial \lambda}{\partial \tau}=0$ if $\tau$ is low enough (in case 1), and $v-p-b-\lambda=0$ we have:

$$
\begin{aligned}
\frac{d \mathcal{L}}{d \tau} & =\frac{\partial \mathcal{L}}{\partial \tau} \\
& =\frac{\partial}{\partial \tau}(b-\psi-\gamma)-\Lambda \frac{\partial}{\partial \tau}(v-p-b-\lambda)-\frac{\partial \Lambda}{\partial \tau}(v-p-b-\lambda) \\
& =-\frac{\partial \gamma}{\partial \tau}+\Lambda \frac{\partial \lambda}{\partial \tau} \\
& =-\frac{\partial \gamma}{\partial \tau} \\
& =-t f_{k}(\underline{k})\left[1-F_{p^{*}}(\bar{p})\right] b<0
\end{aligned}
$$


It follows that the manager's participation constraint, $b-\psi-\gamma>0$, becomes more stringent and hence deal frequency decreases as $\tau$ increases

\section{B Full panel analysis}

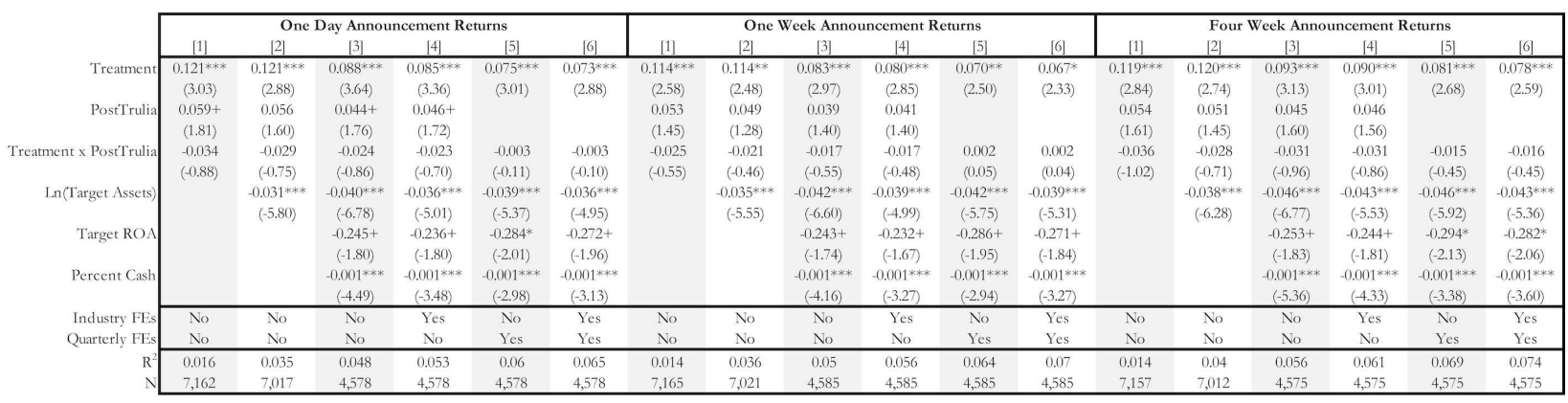

(a) Panel A: Treatment $=$ All US Targets (Jan. 2011 - Dec. 2018)

\begin{tabular}{|c|c|c|c|c|c|c|c|c|c|c|c|c|c|c|c|c|c|c|}
\hline & \multicolumn{6}{|c|}{ One Day Announcement Returns } & \multicolumn{6}{|c|}{ One Week Announcement Returns } & \multicolumn{6}{|c|}{ Four Week Announcement Returns } \\
\hline \multirow[b]{2}{*}{ Treatment } & [1] & [2] & [3] & [4] & {$[5]$} & [6] & [1] & {$[2]$} & [3] & [4] & [5] & {$[6]$} & [1] & [2] & [3] & [4] & [5] & {$[6]$} \\
\hline & $0.141^{* * * *}$ & $0.139 * * * *$ & $0.108^{* * * *}$ & $0.102 * * *$ & $0.099 * * *$ & $0.092^{* * * *}$ & $0.132^{* * * *}$ & $0.131^{* * * *}$ & $0.101 * * *$ & $0.094^{* * * *}$ & $0.092 * * *$ & $0.085^{* * * *}$ & $0.133^{* * *}$ & $0.133^{* * * *}$ & $0.107 * * *$ & $0.101^{* * * *}$ & $0.099 * * * *$ & $0.092 * * *$ \\
\hline & $(3.30)$ & (3.13) & $(4.33)$ & $(4.04)$ & (3.55) & $(3.43)$ & $(2.82)$ & $(2.70)$ & (3.53) & (3.32) & (2.98) & (2.78) & $(3.03)$ & (2.92) & (3.61) & (3.45) & (3.05) & $(2.89)$ \\
\hline \multirow[t]{2}{*}{ PostTrulia } & $0.059+$ & 0.056 & 0.044 & $0.046+$ & & & 0.053 & 0.049 & 0.039 & 0.041 & & & 0.054 & 0.051 & 0.045 & 0.046 & & \\
\hline & $(1.81)$ & $(1.58)$ & (1.64) & $(1.65)$ & & & (1.45) & (1.28) & (1.34) & (1.35) & & & (1.61) & (1.44) & (1.52) & $(1.47)$ & & \\
\hline \multirow[t]{2}{*}{ Treatment x PostTrulia } & -0.069 & -0.063 & -0.05 & -0.048 & -0.036 & -0.034 & -0.059 & -0.053 & -0.043 & -0.04 & -0.03 & -0.028 & -0.058 & -0.053 & -0.049 & -0.046 & -0.038 & -0.036 \\
\hline & $(-1.64)$ & $(-1.52)$ & $(-1.64)$ & $(-1.27)$ & $(-1.09)$ & $(-0.92)$ & $(-1.24)$ & $(-1.12)$ & $(-1.39)$ & $(-1.08)$ & $(-0.88)$ & $(-0.75)$ & $(-1.41)$ & $(-1.27)$ & $(-1.54)$ & $(-1.27)$ & $(-1.08)$ & $(-0.96)$ \\
\hline \multirow[t]{2}{*}{$\operatorname{Ln}$ (Target Assets) } & & $-0.028^{* * *}$ & $-0.037 * * *$ & $-0.033^{* * *}$ & $-0.037 * * *$ & $-0.033^{* * *}$ & & $-0.032^{* * *}$ & $-0.039 * * *$ & $-0.035^{* * *}$ & $-0.039^{* * *}$ & $-0.035^{* * *}$ & & $-0.034 * * *$ & $-0.042^{* * *}$ & $-0.039 * * *$ & $-0.043 * * *$ & $-0.039 * * *$ \\
\hline & & $(-4.81)$ & $(-5.75)$ & $(-4.00)$ & $(-4.67)$ & $(-4.19)$ & & $(-4.51)$ & $(-5.70)$ & $(-4.09)$ & $(-5.07)$ & $(-4.61)$ & & $(-5.26)$ & $(-5.82)$ & $(-4.97)$ & $(-5.35)$ & $(-4.77)$ \\
\hline \multirow[t]{2}{*}{ Target ROA } & & & -0.234 & -0.213 & $-0.276+$ & $-0.252+$ & & & -0.227 & -0.199 & $-0.273+$ & -0.243 & & & -0.241 & -0.217 & $-0.286+$ & -0.26 \\
\hline & & & $(-1.51)$ & $(-1.44)$ & $(-1.80)$ & $(-1.70)$ & & & $(-1.37)$ & $(-1.23)$ & $(-1.66)$ & $(-1.49)$ & & & $(-1.44)$ & $(-1.32)$ & $(-1.78)$ & $(-1.61)$ \\
\hline Percent Cash & & & $\begin{array}{c}-0.001 * * * \\
(-3.74)\end{array}$ & $\begin{array}{c}-0.001 * * * \\
(-3.01)\end{array}$ & $\begin{array}{c}-0.001^{* * * *} \\
(-2.80)\end{array}$ & $\begin{array}{c}-0.001 * * * * \\
(-2.77)\end{array}$ & & & $\begin{array}{c}-0.001 * * * \\
(-3.50)\end{array}$ & $\begin{array}{c}-0.001 * * * \\
(-2.75)\end{array}$ & $\begin{array}{c}-0.001 * * * \\
(-2.81)\end{array}$ & $\begin{array}{c}-0.001 * * * * \\
(-2.92)\end{array}$ & & & $\begin{array}{c}-0.001 * * * * \\
(-3.71)\end{array}$ & $\begin{array}{c}-0.001^{1 * * * *} \\
(-4.02)\end{array}$ & $\begin{array}{c}-0.001 * * * \\
(-3.04)\end{array}$ & $\begin{array}{c}-0.001 * * * * \\
(-2.96)\end{array}$ \\
\hline \multirow{4}{*}{$\begin{array}{l}\text { Industry FEs } \\
\text { Quarterly FEs }\end{array}$} & No & No & No & Yes & $\frac{(-2.80)}{\text { No }}$ & $\frac{(-2.1 /)}{\text { Yes }}$ & No & No & $\frac{(-3.50)}{\text { No }}$ & $\frac{(-2 . / 5)}{\text { Yes }}$ & $\frac{(-2.81)}{\text { No }}$ & $\frac{(-2.92)}{\text { Yes }}$ & No & No & No & $\frac{(-4,02)}{\text { Yes }}$ & No & $\frac{(2,2,0)}{\text { Yes }}$ \\
\hline & No & No & No & No & Yes & Yes & No & No & No & No & Yes & Yes & No & No & No & No & Yes & Yes \\
\hline & 0.014 & 0.03 & 0.045 & 0.052 & 0.06 & 0.067 & 0.012 & 0.031 & 0.046 & 0.054 & 0.064 & 0.071 & 0.012 & 0.033 & 0.05 & 0.057 & 0.067 & 0.075 \\
\hline & 6,251 & 6,133 & 3,900 & 3,900 & 3,900 & 3,900 & 6,251 & 6,134 & 3,905 & 3,905 & 3,905 & 3,905 & 6,244 & 6,125 & 3,895 & 3,895 & 3,895 & 3,895 \\
\hline
\end{tabular}

(b) Panel B: Treatment = Only Delaware Targets (Jan. 2011 - Dec. 2018)

Note: Each panel presents OLS estimations with industry- and year-clustered standard errors on several dependent variables corresponding to natural log of the 1-day, 1-week and 4-week gross stock price premium on announcement date, for public target acquisitions in excess of $\$ 100 \mathrm{~m}$ deal value where at least $50 \%$ of voting shares are sought. The January 2016 Trulia decision in the Delaware Chancery Court is the common treatment event, and the coefficient on the cross-product Treatment x PostTrulia is the diff-in-diff estimate. Foreign targets constitute the control group. Panel A reports estimates where all US targets are part of the treatment group, while Panel B drops non- Delaware US targets from the data set. Estimated t-statistics are in parentheses. Notation: $\left\{+,{ }^{*}, * *, * * *\right\}$ denote significance at the $p=\{0.10,0.05,0.02,0.01\}$ levels (2-sided test). Data Source: Thompson Reuters SDC Platinum Database (Jan. 2011 - Dec. 2018).

Table 13: Difference in Difference Results (full panel) 